\title{
LA ENTONACIÓN DE (DES)CORTESÍA EN CATALÁN
}

\author{
Empar Devís Herraiz
}

Departament d'Educació Lingüística i Literària (i DCEM), Universitat de Barcelona

devis@ub.edu

Recibido: 1 de julio de 2020

Aceptado: 17 de noviembre de 2020

\begin{abstract}
Resumen
En este trabajo presentamos una descripción de los rasgos melódicos de (des)cortesía del catalán, a través del análisis acústico y su posterior validación perceptiva. Para realizar el estudio de la fase acústica, hemos contado con el corpus de habla espontánea elaborado por Font-Rotchés (2006), mientras que para la fase perceptiva se ha recopilado un corpus propio. La metodología utilizada para el análisis de los datos acústicos y de los tests perceptivos es el Análisis Melódico del Habla propuesto por Cantero (2002). Los resultados reflejan que existe un código semiestable para la expresión de la (des)cortesía melódica del catalán, pero al mismo tiempo también muestran el carácter amplio del fenómeno, que excede los límites estrictos del código idiomático, permitiendo su análisis interlingüístico.
\end{abstract}

Palabras clave: entonación, cortesía, descortesía, catalán

\section{Resum}

En el present treball presentem una descripció dels trets melòdics de (des)cortesia del català, a partir de l'anàlisi acústica i de la posterior validació perceptiva. Per realitzar l'estudi de la fase acústica, hem comptat amb el corpus de parla espontània elaborat per Font-Rotchés (2006), mentre que per a la fase perceptiva $\mathrm{s}$ 'ha creat un corpus propi. El mètode utilitzat per fer l'anàlisi de les dades acústiques i dels tests perceptius és l'Anàlisi Melòdica de la Parla proposat per Cantero (2002). Els resultats reflecteixen que existeix un codi semiestable per a l'expressió de la (des)cortesia melòdica del català, però, al mateix temps, també mostren el caràcter ampli del fenomen, que sobrepassa els límits estrictes del codi idiomàtic, i permet la seva anàlisi interlingüística.

Paraules clau: entonació, cortesia, descortesia, català

\begin{abstract}
In this paper we introduce a descriptive model of the melodic features of politeness and impoliteness expressions in Catalan, based on acoustic analysis and their subsequent perceptual validation. To carry out the study of the acoustic phase we counted on the spontaneous speech corpus elaborated by Font-Rotchés (2006), while for the perceptual phase we compiled our own corpus. The methodology used to analyze the acoustic data is the Melodic Analysis of Speech proposed by Cantero (2002). The results of the analysis reflect that there is a semi-stable code for the expression of the melodic discourtesy of Catalan, but at the same time they also show the broad nature of the phenomenon, which exceeds the strict limits of the idiomatic code, allowing its interlinguistic analysis.
\end{abstract}

Keywords: intonation, politeness, impoliteness, Catalan 


\section{INTRODUCCIÓN}

El estudio formalizado de la cortesía verbal comienza en los años 70 y 80 con la aparición de las tres teorías fundadoras: la de Lakoff (1973), la de Leech (1983) y la de Brown y Levinson (1987). El tema ha suscitado gran interés en las últimas décadas y, gracias a ello, se ha conseguido describir con detalle el fenómeno de la cortesía también para el catalán (Payrató, 1988). Se ha indagado, por ejemplo, en el uso de diferentes estrategias pragmáticas (Magraner, 2018); se ha dado cuenta de los contextos socioculturales que subyacen a los comportamientos de dicho fenómeno (Hernández, 2002); se han promovido estudios contrastivos entre distintas lenguas (Herrero y Devís, 2020) y se han desarrollado modelos teóricos alternativos a las teorías fundadoras (Albelda et al., 2014). El estudio de los rasgos prosódicos que aportan (des)cortesía a la conversación tardó un poco más en llegar, pero actualmente contamos con una serie muy interesante de trabajos en diferentes lenguas. Para el español podemos destacar: Roldán (2000), Álvarez y Blondet (2003), Hidalgo (2006, 2007, 2009), Orozco (2008), Devís (2011). Y para el catalán: Payà (2003), Astruc (2008), Nadeu (2008), Nadeu y Prieto (2011), Devís y Cantero (2014) o Roseano et al. (2015).

La cortesía se entiende como fenómeno con valores y efectos en el nivel social de la lengua y como herramienta de relación social con fines estratégicos en la comunicación, en función de los intereses de los interlocutores. Por cortesía atenuadora entendemos las estrategias que el hablante utiliza para suavizar en lo posible sus imposiciones o para salvaguardar la imagen negativa y la autoestima del interlocutor (Haverkate, 1994: 117). Mientras que por descortesía se entiende el fenómeno contrario, es decir, sus efectos perjudican las relaciones sociales entre los interlocutores y, aunque también se emplea con fines estratégicos, el fin no es el de la cooperación sino más bien el de la confrontación (Albelda 2005: 329). El mecanismo lingüístico utilizado para crear estos efectos corteses es la atenuación, en cambio para crear efectos descorteses es la intensificación. En este estudio, nos centraremos exclusivamente en los mecanismos lingüísticos atenuadores e intensificadores de tipo melódico en el nivel suprasegmental.

La función de la atenuación y de la intensificación en el nivel suprasegmental corresponde fundamentalmente a la entonación, por este motivo los rasgos melódicos suelen ser determinantes a la hora de interpretar un enunciado como más o menos cortés. Autores como Quilis (1988, 1993), Hidalgo (2001, 2006, 2007, 2009), Waltereit (2005), Haverkate (1994), Álvarez y Blondet (2003), Briz e Hidalgo (2008) y Devís (2011) han podido observar para el español cómo ciertas formas entonativas cumplen, habitualmente, una función de atenuación o mitigación en enunciados que podrían contener algún tipo de "agresividad" implícita. Mientras en Devís (2011) se pudo demostrar que existen otras formas entonativas que a través de la intensificación cumplen una función a nivel suprasegmental para marcar la descortesía. Para el catalán el fenómeno de los rasgos prosódicos de la cortesía también ha empezado a causar interés entre los investigadores, como hemos citado previamente, y creemos que en los próximos años se completarán incluso con información multidimensional (verbal, kinésica y prosódica) gracias a los avances de la tecnología.

En este trabajo ${ }^{1}$ el foco de estudio se centrará, exclusivamente, en la delimitación de los rasgos melódicos conducentes a la creación de efectos contextuales (des)corteses en catalán, sin entrar en los efectos de otros rasgos prosódicos. La combinación con los

\footnotetext{
${ }^{1}$ El trabajo es fruto de la colaboración con el proyecto de investigación Análisis melódico del habla y modelos didácticos, subvencionado por MICINN (Ministerio de Ciencia e Innovación de España). Referencia: FFI2013-41915-P
} 
demás rasgos prosódicos es una cuestión que consideramos de sumo interés y que en futuras investigaciones tendremos en consideración.

Los resultados obtenidos han sido validados mediante pruebas perceptivas, y confirman las hipótesis de que existe un código semiestable para la expresión de la descortesía melódica del catalán, pero también nos confirman que el código semiestable existente no forma parte del código lingüístico de la lengua catalana (que en la entonación serían exclusivamente los rasgos fonológicos), compartido por todos los hablantes del idioma, sino de los códigos paralingüísticos, compartidos no por todos los hablantes del idioma sino por una comunidad de habla determinada (Cantero y Mateo, 2011). En este sentido, el código descrito para el español, que sirve para expresar una entonación descortés, también funcionaría en catalán. De hecho, los rasgos encontrados, coinciden en gran medida con la clasificación elaborada para el español (Devís, 2011).

\section{METODOLOGÍA}

Para el análisis de los datos se ha aplicado el método AMH. Análisis Melódico del Habla (Cantero, 2002). El punto de partida es la definición de la entonación a partir de las variaciones de F0 que cumplen una función lingüística a lo largo de la emisión de voz.

Consideramos que la entonación funciona en tres niveles:

- Prelingüístico: comprende los fenómenos del acento, el ritmo y la melodía, que funcionan solidariamente como elementos fónicos coestructuradores del discurso, al margen de cualquier otra dimensión significativa. En este nivel, se considera la entonación como un "contenedor" lingüístico, integrando y delimitando las unidades del discurso. Es lo que Quilis (1993) llamaba "función delimitadora" y "función integradora" de la entonación. Los rasgos melódicos característicos de este nivel son rasgos fonéticos, bien concretos.

- Lingüístico: Comprende las características melódicas cuyo rendimiento fonológico permite caracterizar y distinguir las unidades funcionales de la entonación, sus "signos lingüísticos". En español fueron identificados ocho tonemas resultantes de la combinación de los rasgos fonológicos ${ }^{2}$ (/ \pm interrogativa, \pm suspendida, \pm enfática/) que conforman los 4 tipos de entonación descritos por el modelo (neutra, interrogativa, suspendida y enfática), cuyos patrones melódicos constituyen las melodías típicas de la lengua ${ }^{3}$.

- Paralingüístico: comprende las variantes melódicas de tales tonemas, dentro de los amplios márgenes de dispersión de cada uno de ellos. Tales melodías permiten expresar emociones particulares, rasgos discursivos idiolectales o de la personalidad del hablante, e incluso pueden estar variablemente codificadas (como ocurre, por ejemplo, en la expresión de la "cortesía”, en Devís, 2011).

El estudio que presentamos ha seguido las dos fases que comprende el método, tal y como describen Cantero y Font- Rotchés $(2009,2020)^{4}$ :

\footnotetext{
2 Los rasgos fonológicos descritos en este nivel son rasgos abstractos, meramente opositivos.

${ }^{3}$ V. en Cantero y Font-Rotchés (2007) un resumen de los patrones melódicos del español; y en FontRotchés $(2007,2011)$ los patrones del catalán.

${ }^{4}$ Recientemente el método ha ampliado su estudio al resto de rasgos prosódicos (Cantero, 2019) y a partir del 2020 ha pasado a llamarse Análisis Prosódico del Habla (APH).
} 


\section{Fase acústica (descriptiva):}

- extracción de la F0 del enunciado;

- determinación de los valores de F0 vocálicos. Se identifican las vocales y se anota su valor medio;

- la sucesión de valores vocálicos genera una curva melódica esencial que elimina los valores irrelevantes;

- en último lugar, cada curva melódica obtenida en $\mathrm{Hz}$ se estandariza en porcentajes para construir una melodía independiente de las características del hablante.

\section{Fase perceptiva (experimental):}

- se sintetiza la melodía resultante (por ejemplo, mediante el programa de análisis Praat) y se substituyen los valores tonales por los valores estandarizados;

- se modifican únicamente los valores del rasgo melódico cuya relevancia queremos comprobar;

- se realiza un experimento perceptivo que permita validar la melodía sintetizada y/o falsar la hipótesis melódica.

\subsection{Corpus}

Los datos que permitieron identificar los rasgos melódicos descorteses, en la fase acústica, fueron extraídos del Corpus oral de parla espontània elaborado por FontRotchés (2006). Siguiendo la propuesta de Cantero (2002: 167), la muestra de habla espontánea se creó a partir de la grabación de programas de televisión con participación de público, dejando de lado otros medios, como la radio, en la que los participantes suelen tener un cierto grado de profesionalización (con lo cual el modelo de lengua no sería espontáneo).

El corpus está compuesto por 20 programas distintos de la televisión catalana (TV3 y Canal 33) y de la franja en catalán de la televisión española (TVE2). También cuenta con 5 ediciones de un programa de debate de $2 \mathrm{~h}$ de duración cada uno que TVE2 ofreció entre el 1999 y el 2000, con la gran participación de personas anónimas que expresaban su punto de vista sobre temas de actualidad muy polémicos.

En total, pues, el corpus de grabaciones consta de 47 horas de material audiovisual, emitido entre el 1996 y el 2000. Los programas contenían reportajes, entrevistas, encuestas en la calle, debates, concursos, tertulias y docudramas, entre otros, en los que abundaba el diálogo.

Para seleccionar los enunciados se tuvieron en cuenta los siguientes criterios:

a) informantes genuinos, con buena vocalización y ningún defecto de habla

b) escoger como máximo 8-10 enunciados de un mismo informante

c) seleccionar fragmentos donde el informante se expresa con naturalidad

d) comprobar que en los enunciados no hay solapamientos de voces, ni música o ruidos de fondo

A partir de estos criterios, el corpus de enunciados definitivo quedó constituido por 580 enunciados, que procedían de 160 informantes (98 hombres, 58\%; y 67 mujeres, 42\%), de edades comprendidas entre 18 y 70 años, y de profesiones muy diversas: médico, guardia, administrativo, gimnasta, fiscal, estudiante, juez, psiquiatra, actor/actriz, 
jubilado, cocinero, campesino, cantante, obrero, pastor, agente inmobiliario... y de distintas procedencias de Cataluña, Valencia y Baleares.

Para la realización de la fase acústica revisamos los 580 enunciados del corpus y seleccionamos los 100 que consideramos más (des)corteses a nuestro oído: 50 corteses y 50 descorteses.

\section{ANÁLISIS DE LOS DATOS DE LA ENTONACIÓN DE CORTESÍA ATENUADORA EN CATALÁN}

\subsection{Fase acústica}

Presentamos a continuación una serie de ejemplos donde se pueden observar los principales rasgos hipotetizados como corteses atenuadores. En las figuras, cada punto de la curva que observamos en el gráfico es un valor vocálico representativo. En el análisis melódico interesan solo los valores vocálicos puesto que el sonido más importante del discurso siempre es la vocal. Cada valor vocálico constituye un segmento tonal de la melodía que suele corresponder a la sílaba (en los gráficos los vemos segmentados por columnas). En la primera línea horizontal tenemos la transcripción ortográfica. Solo en los casos en los que la duración de la vocal es significativamente mayor (no una sino dos moras de duración), podemos suponer que la vocal constituye no uno sino dos segmentos tonales: en tales casos, la vocal contiene un inflexión tonal, que se define, precisamente, como la sucesión de dos (o más) segmentos tonales en una vocal (en la figura 1 observamos una vocal con dos segmentos tonales "no": el segundo lo transcribimos con un asterisco). Segmento tonal, por tanto, es cada valor de F0 relevante en la melodía; consideramos que hay dos segmentos tonales cuando el porcentaje de ascenso o de descenso es igual o superior al $10 \%{ }^{5}$.

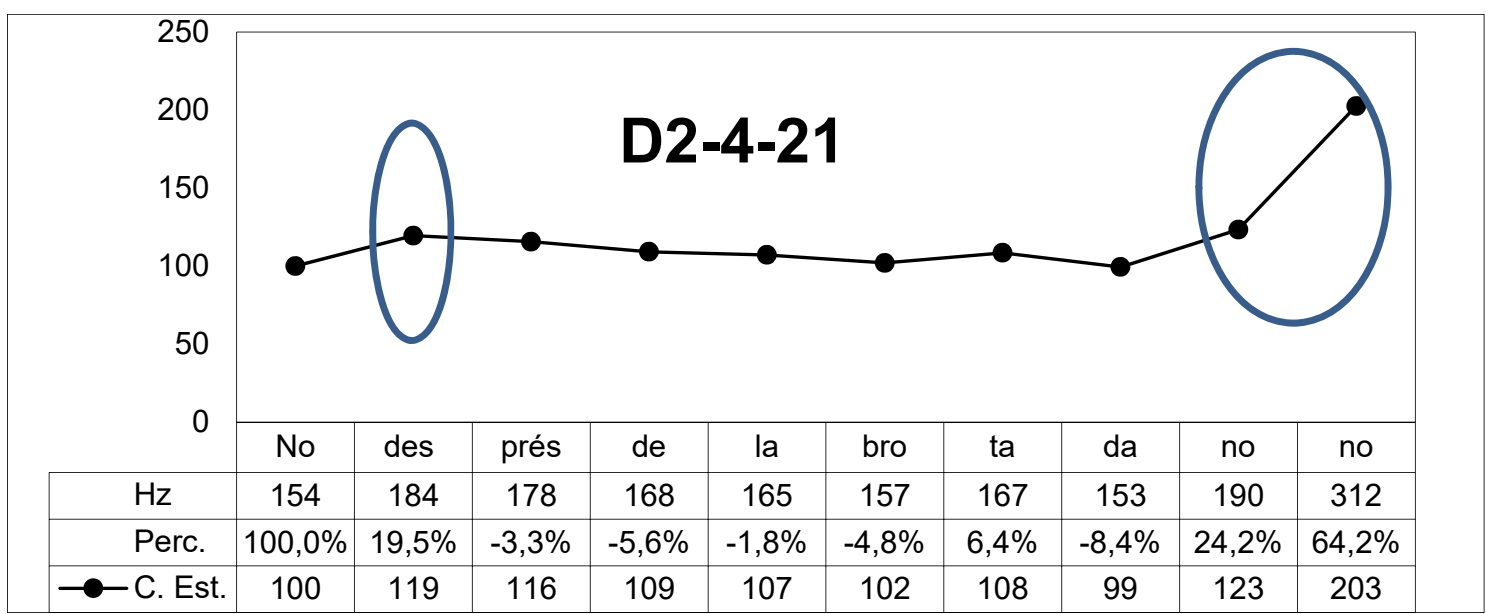

Figura 1. Melodía estandarizada del enunciado: No, després de la brotada no! (¡No, después de haber brotado no!).

En la segunda línea horizontal observamos los valores en Hercios (valores absolutos obtenidos a partir de las vocales), y en la tercera observamos los porcentajes de ascenso $\mathrm{y}$ de descenso. El primer valor es $100 \%$ - un número arbitrario-, a partir del cual se anotan los tantos por ciento de desnivel entre un segmento y el siguiente, para obtener los valores relativos: la última línea muestra los valores de la curva estandarizada a

\footnotetext{
${ }^{5}$ V. Cantero (1999).
} 
partir de los porcentajes de ascenso y de descenso. Cada gráfico muestra la representación de esta curva estándar. El método AMH trabaja siempre a partir de curvas estandarizadas porque solo la relativización de cada valor tonal con respecto al valor anterior permite construir la melodía tal cual es, independientemente de las características del hablante.

La figura 1 presenta un grupo fónico con una declinación muy plana y una inflexión final ascendente $(64,2 \%)$, teniendo en cuenta la clasificación de Font-Rotchés (2007:102): desde el punto de vista de la entonación lingüística ${ }^{6}$ es, por tanto, una melodía /+suspendida/; en este contexto, y a nivel pragmático, funciona como rasgo atenuador para mitigar la agresividad implícita de la orden. Esta transposición funcional del contorno entonativo /+ suspendido/ que a nivel pragmático actúa como mecanismo atenuador ya había sido identificado precedentemente por Hidalgo (2009). La prominencia en la vocal átona de la sílaba "des", desde el punto de vista de la entonación paralingüística ${ }^{7}$, se convierte también en una clave acústica relevante para distinguir un enunciado cortés de uno neutro, muy recurrente en todos los ejemplos analizados, y que provoca un ritmo melódico que distingue y caracteriza las emisiones corteses atenuadoras.

La figura 2 presenta la misma estructura del enunciado anterior, con una inflexión final suspendida en ascenso $(+47,8 \%)$, aunque, en este caso, con el primer pico en la primera vocal tónica. El reproche queda atenuado con el final ascendente.

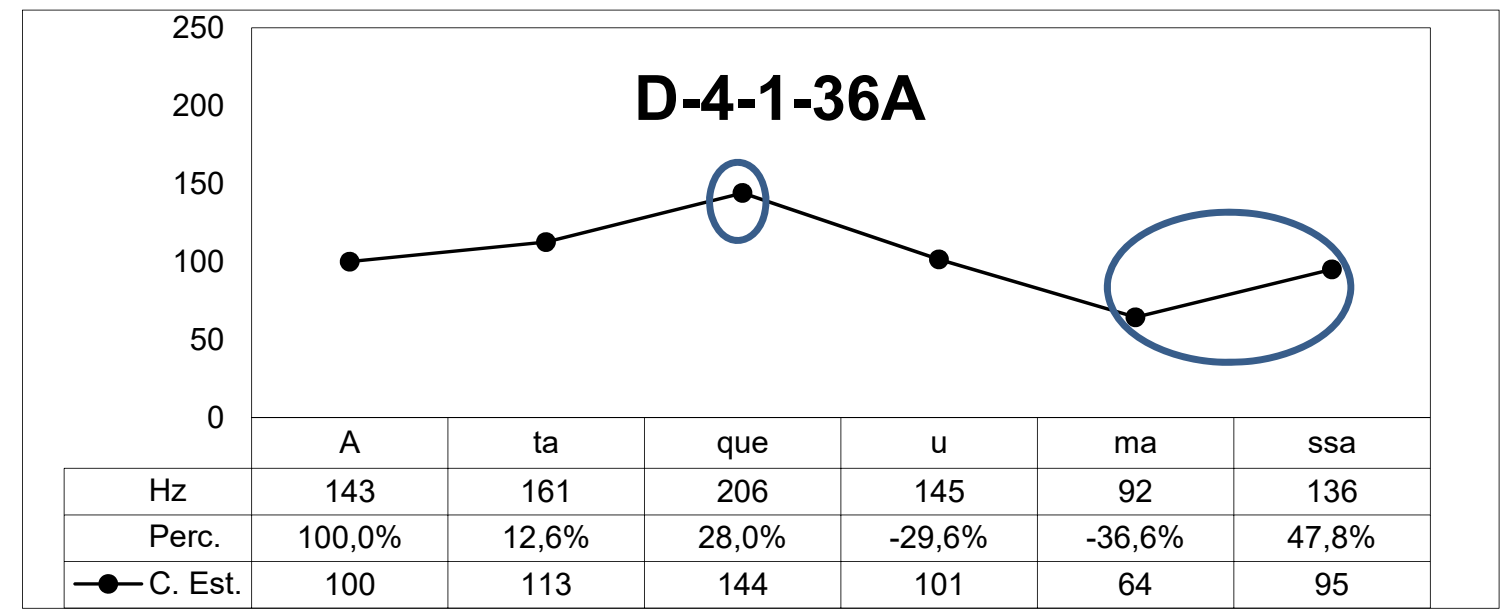

Figura 2. Melodía estandarizada del enunciado: Ataqueu massa! (¡Atacáis demasiado!).

La figura 3 presenta nuevamente una pequeña prominencia en una vocal átona "ta", aunque en este caso con una inflexión final descendente. Este tipo de inflexiones descendentes fueron muy recurrentes en los enunciados atenuados de nuestro corpus.

\footnotetext{
${ }^{6}$ Por nivel lingüístico nos referimos al segundo nivel de entonación descrito por Cantero (2002).

${ }^{7}$ El nivel paralingüístico es el tercer nivel de entonación descrito por Cantero (2002).
} 


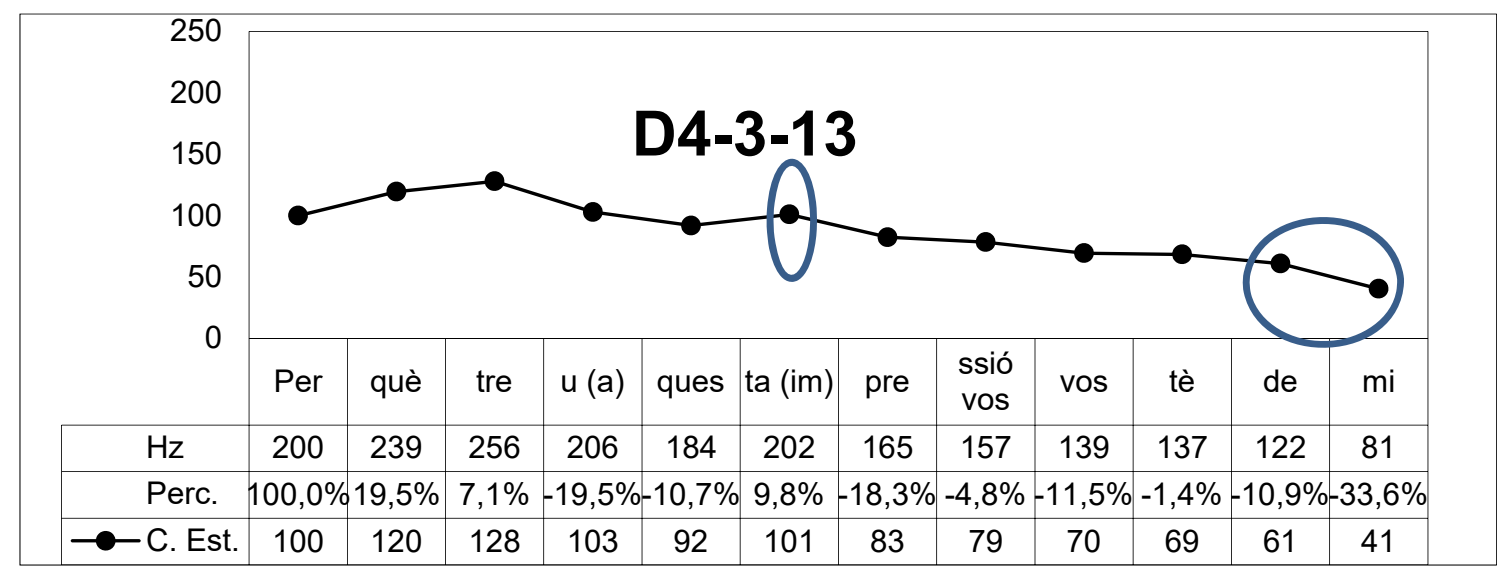

Figura 3. Melodía estandarizada del enunciado: Per què treu aquesta impressió vostè de mi? (¿Por qué saca esta impresión usted de mí?).

En la figura 4 aparece el mismo esquema (prominencia en átona y final descendente).

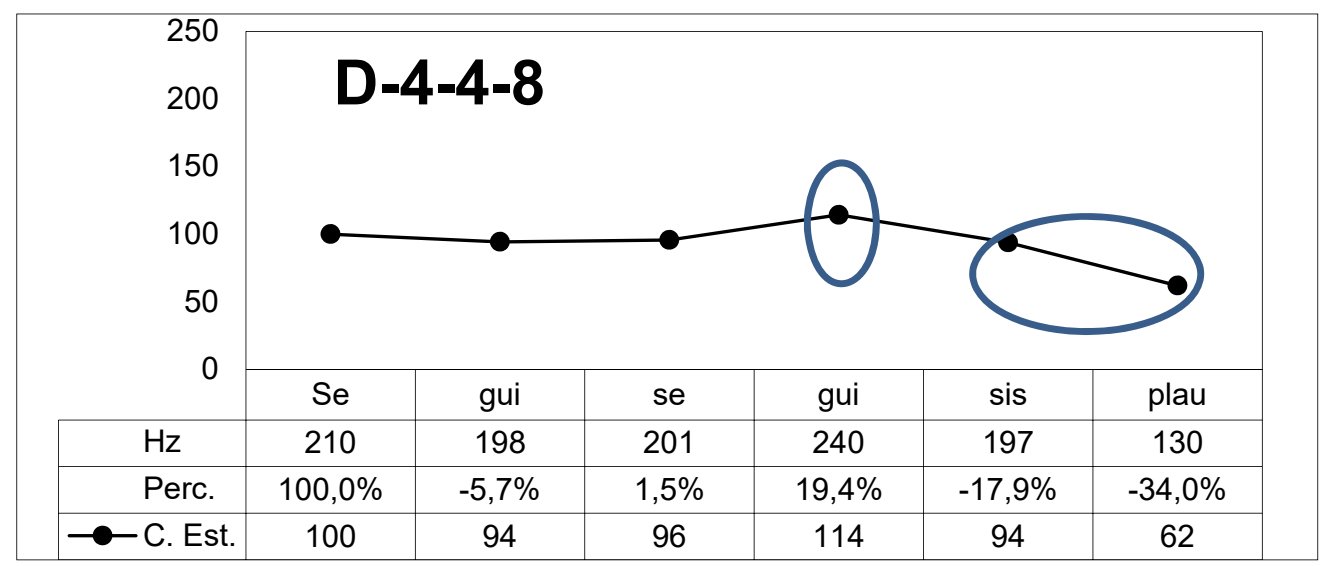

Figura 4. Melodía estandarizada del enunciado: Segui, segui, si us plau (Siéntese, siéntese, por favor).

Otro rasgo que observamos frecuentemente es el énfasis de palabra. En la figura 5 vemos cómo la palabra "defensa" se enfatiza con un esquema tonal de énfasis de palabra, con ascensos hasta el $45 \%$, y rompiendo totalmente la declinación; también observamos, de nuevo, una inflexión final descendente, aunque esta vez comenzando desde la vocal pretónica (prominencia tonal en átona).

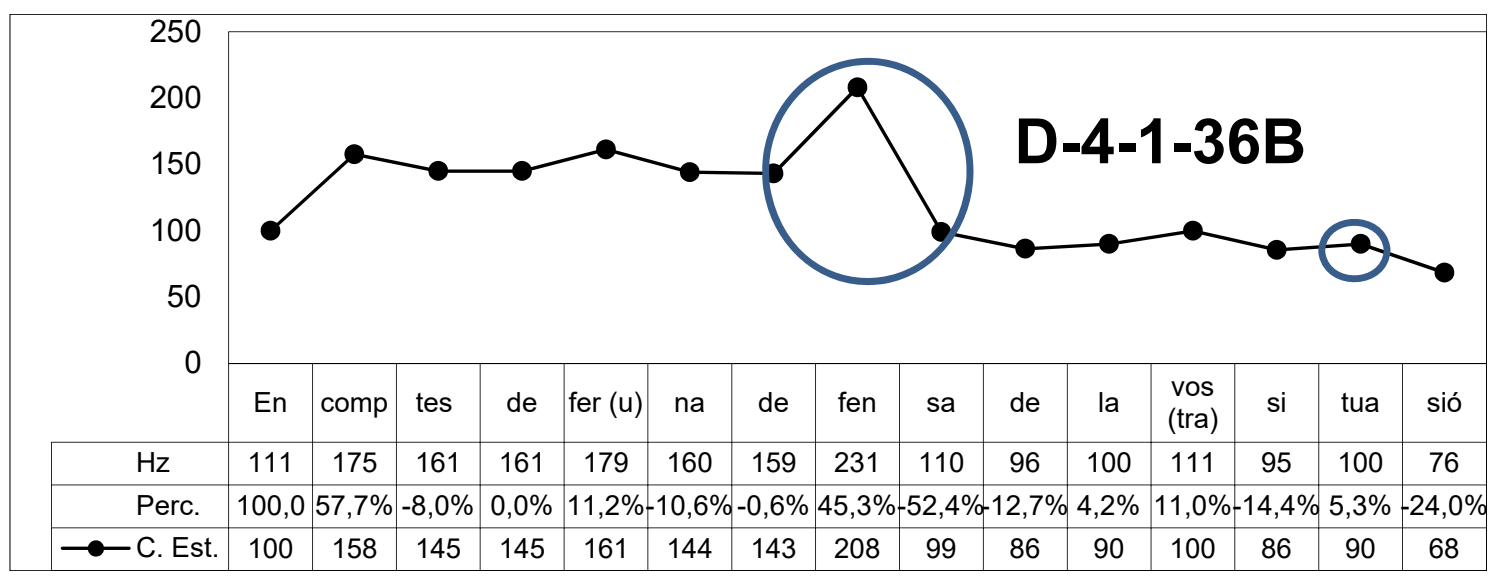

Figura 5. Melodía estandarizada del enunciado: en comptes de fer una defensa de la vostra situació (en vez de hacer una defensa de vuestra situación). 
En la figura 6 observamos una melodía prácticamente plana, con poca declinación, que parte de un primer pico en vocal postónica (prominencia en átona) y constituida a base de énfasis de palabra, con un final suspendido. La queja de la informante es muy dura, así que los rasgos melódicos atenúan esa dureza.

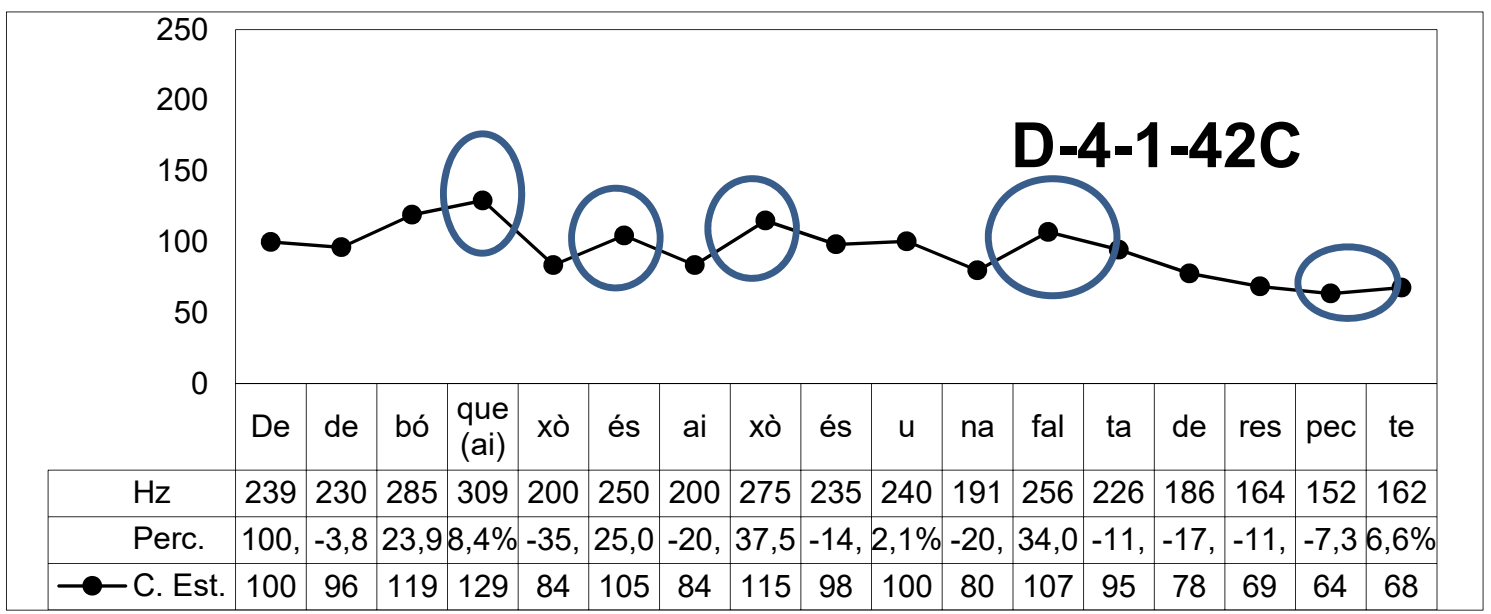

Figura 6. Melodía estandarizada del enunciado: De debò que això és això és una falta de respecte (De verdad que esto es esto es una falta de respeto).

Otro rasgo relevante para marcar la cortesía es la inflexión final con núcleo elevado. En la figura 7 vemos un primer pico en átona y una inflexión final de este tipo que atenúan la orden.

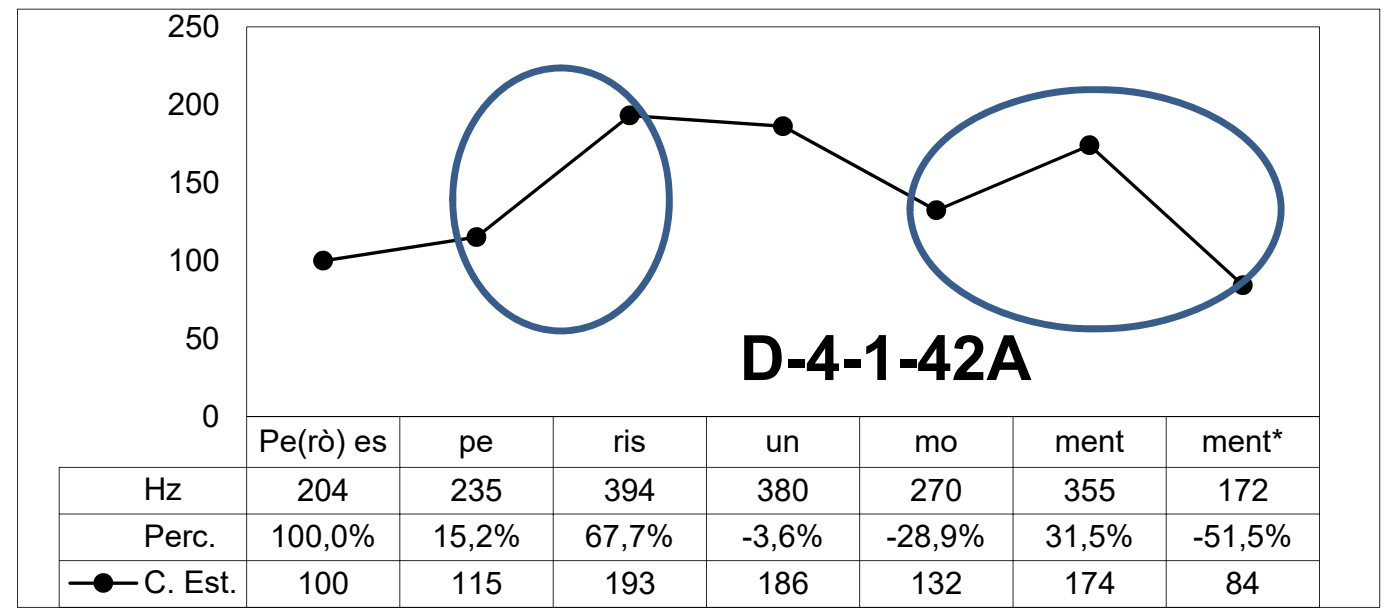

Figura 7. Melodía estandarizada del enunciado: Però esperi's un moment (Pero aguarde un momento).

Los datos analizados, pues, nos permitieron establecer una serie de rasgos melódicos responsables de mitigar enunciados descorteses o que podrían contener algún tipo de "agresividad" léxico-gramatical implícita. A partir de ellos, elaboramos la siguiente hipótesis:

1) Inflexión final:

- Inflexión final /+ suspendida/ (con ascenso final entre el 15 y el 70\%)

- Inflexión final neutra (con descenso entre el 20 y el 40\%)

- Inflexión final con núcleo elevado (entre el 10 y el 50\%) 
2) Cuerpo del contorno:

- Prominencia en átonas (con ascensos entre el 10 y el 30\%)

- Declinaciones muy planas

- Primer pico desplazado o ausente

- Énfasis de palabra (foco estrecho) con ascenso hasta el 45\%

Estos rasgos coinciden, esencialmente, con los que en investigaciones anteriores (Devís, 2011) habíamos identificado en español coloquial; sin embargo, en nuestro corpus no aparecieron otros rasgos que en español son muy relevantes, como las inflexiones internas y las inflexiones finales interrogativas. Decidimos, pues, incorporar a la fase perceptiva también estos últimos, con el objeto de determinar los rasgos melódicos diferenciales en los dos idiomas.

\subsection{Fase perceptiva}

Para poder validar los rasgos hipotetizados como corteses atenuadores se configuró un corpus específico creado ad hoc, en el que los enunciados eran claramente descorteses desde el punto de vista léxico-gramatical, para poder asegurar que los rasgos exclusivamente melódicos introducidos en las manipulaciones eran los únicos responsables de aportar atenuación. Se grabaron 4 insultos u ofensas, 4 órdenes y 6 confrontaciones; los 14 enunciados fueron grabados por un hombre y por una mujer, dando un total de 28 enunciados originales, los cuales fueron posteriormente manipulados con el programa de análisis acústico Praat. Los enunciados grabados fueron los siguientes:

- Insultos/ofensas: Ets un fill de puta (eres un hijo de puta), Ves-te'n a cagar (vete a cagar), Ets imbècil (eres imbécil), Em fas fàstic, tio (me das asco, tío).

- Órdenes: Tanca la porta (cierra la puerta), Dona'm la mà (dame la mano), Calla ja (cállate ya), Vine aquí (ven aquí).

- Confrontaciones: No estic d'acord amb tu (no estoy de acuerdo contigo), Això és mentida (eso es mentira), No em sembla bé (no me parece bien).

En primer lugar, manipulamos solo las inflexiones finales, de los 28 enunciados se eligieron 14; algunos de la voz femenina y otros de la masculina, más uno con las dos voces, lo que nos permitió crear 16 versiones con este tipo de manipulación. En segundo lugar, manipulamos solo algún rasgo interno (prominencia en átonas, énfasis de palabra, inflexiones internas...), dejando el resto del enunciado original, lo que permitió crear un total de 16 versiones más. Finalmente, procedimos a las manipulaciones combinadas: escogimos los 16 enunciados que contenían la manipulación de un rasgo interno y le añadimos una inflexión final diferente a la original (suspendida, descendente, interrogativa o de núcleo elevado).

En total, creamos 48 versiones manipuladas. Posteriormente, elaboramos un test perceptivo, cada uno para 33 oyentes, en total los test fueron validados por 99 oyentes hablantes nativos de catalán, todos estudiantes universitarios de la Universidad de Barcelona. Para cada test se eligieron 12 enunciados originales, los mismos para cada test y una versión manipulada de cada uno. De este modo se pudieron validar 36 versiones donde se combinaban los tres tipos de manipulación.

Los objetivos fueron definir si los rasgos melódicos hipotetizados en la fase acústica podían por si solos o en interacción crear un efecto de atenuación en enunciados que 
originalmente no habían sido pronunciados con esta intención, confirmando así la existencia de un código semiestable para la expresión de la cortesía melódica también en catalán. Y también comparar los resultados con la descripción elaborada para el español coloquial (Devís, 2011), para comprobar si son códigos lingüísticos diferentes o si son compartidos no por todos los hablantes del idioma sino por una comunidad de habla determinada.

En los subapartados siguientes, mostramos algunos ejemplos de enunciados analizados y su respectiva manipulación.

\subsubsection{Insultos}

La figura 8 muestra uno de los enunciados creados ad hoc para su posterior manipulación, donde observamos una declinación plana con una inflexión final descendente.

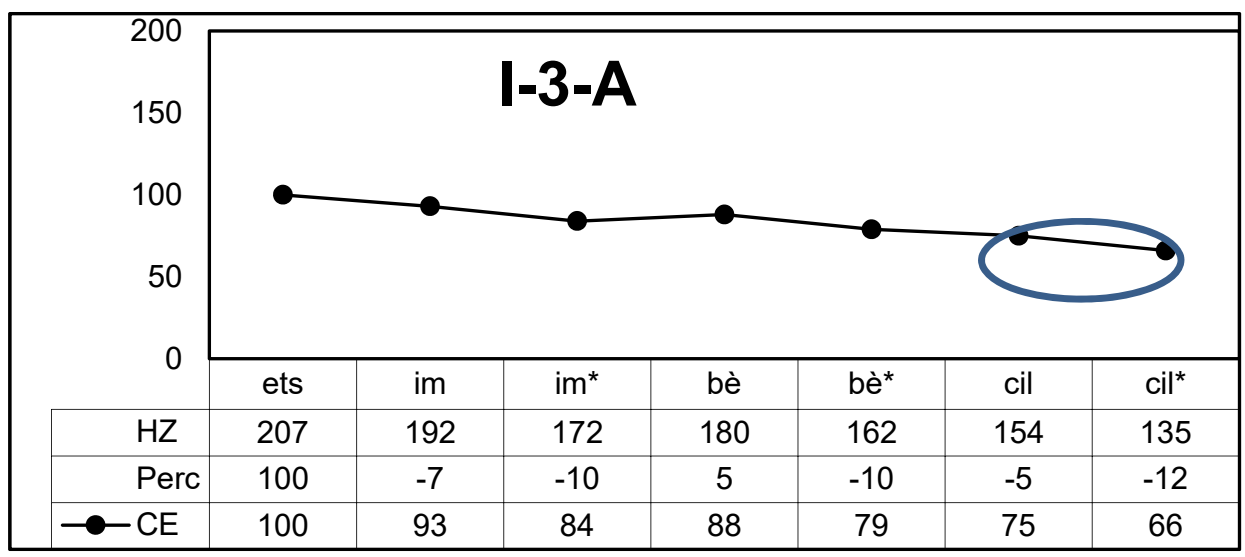

Figura 8. Enunciado original estandarizado del insulto: Ets imbècil (Eres imbécil).

La figura 9 muestra la manipulación del mismo enunciado original, incorporando solo una inflexión final interrogativa (un ascenso de un 70\% o superior) y dejando el resto del enunciado original. La inflexión final empieza en la última vocal tónica hasta el final del enunciado (imbècil).

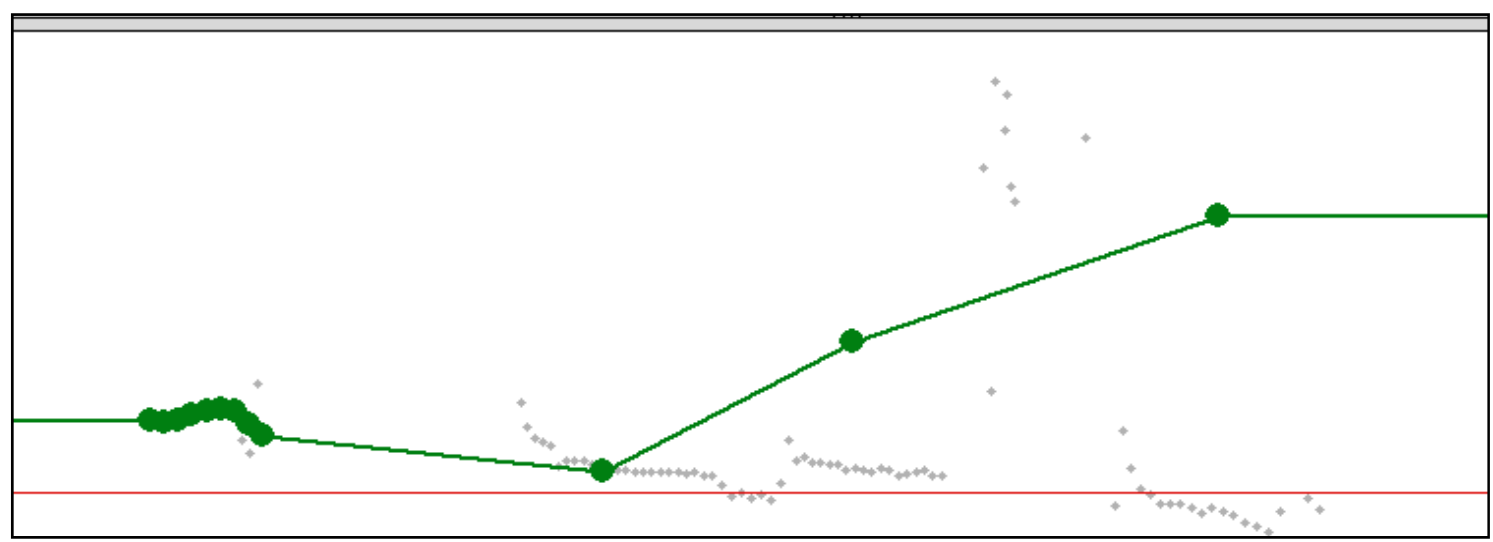

Figura 9. Manipulación del mismo enunciado con inflexión final interrogativa.

\subsubsection{Confrontaciones}

La figura 10 muestra el enunciado original relativo a una confrontación con un primer pico en la primera sílaba "no" con un ascenso del 17\%, un cuerpo en descenso y una inflexión final descendente (-18\%). 


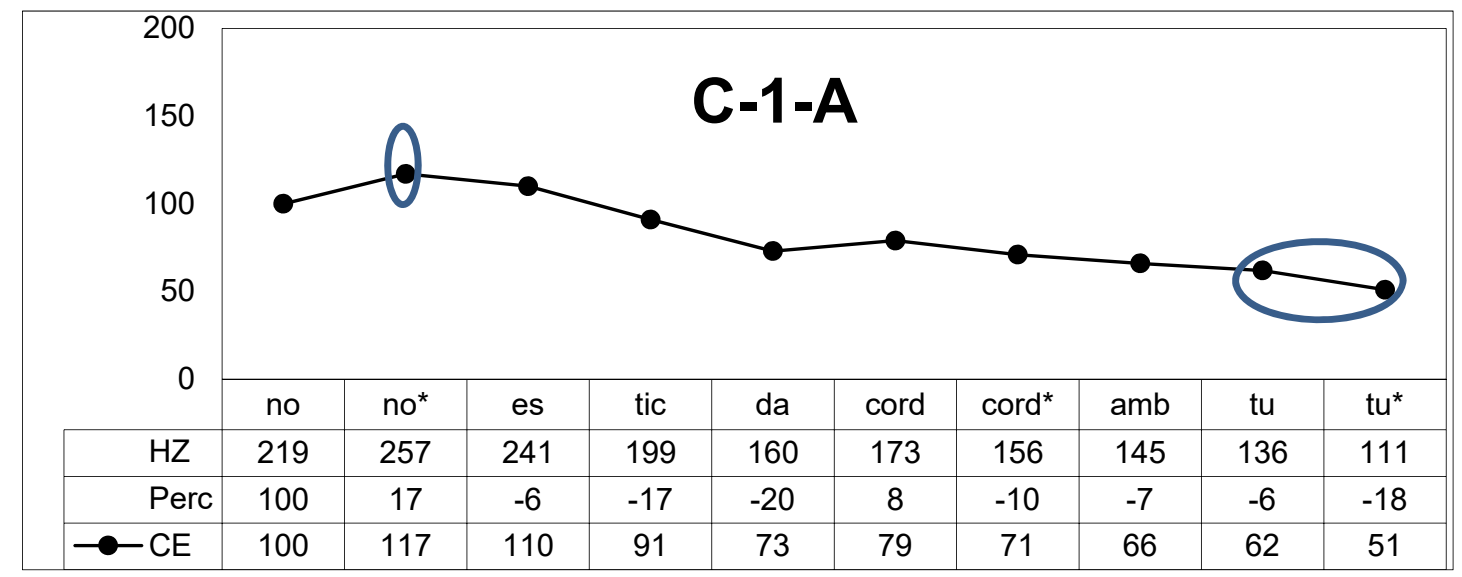

Figura 10. Enunciado original estandarizado de la confrontación: No estic d'acord amb tu (No estoy de acuerdo contigo).

La figura 11 muestra la manipulación del anterior enunciado original. En este caso se ha

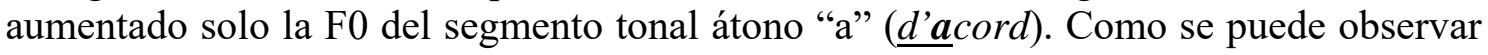
en la figura 10, este segmento tonal tenía una F0 inferior a la tónica que le precedía.

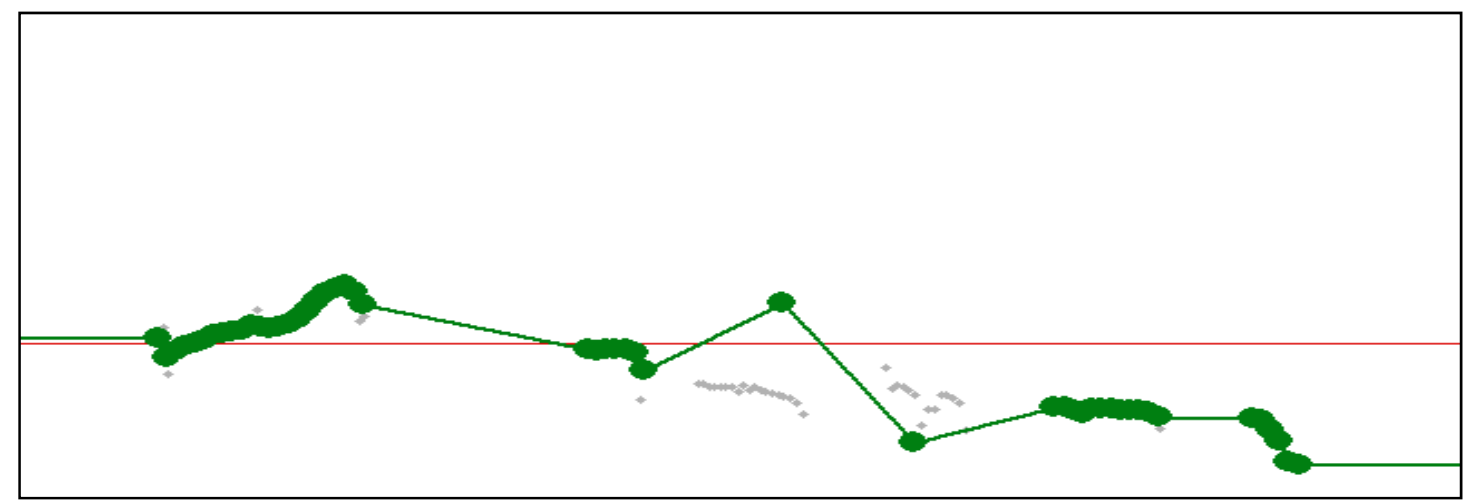

Figura 11. Manipulación del mismo enunciado con una prominencia en vocal átona.

\subsection{3 Órdenes}

La figura 12 muestra el enunciado original relativo a una orden con un primer pico situado en la postónica y un cuerpo en descenso hasta el final.

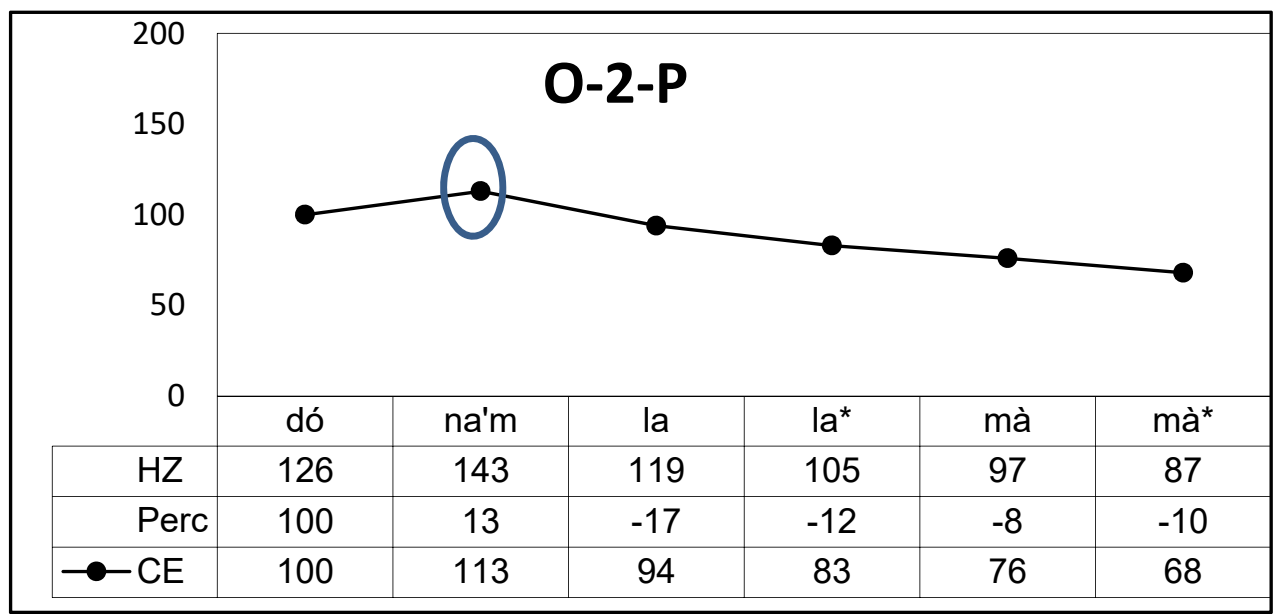

Figura 12. Enunciado original estandarizado de la orden: Dóna'm la mà (Dame la mano). 
La figura 13 muestra una manipulación combinada del mismo enunciado original. Como se puede observar, se han introducido dos inflexiones internas ascendentes en los segmentos tonales iniciales y una inflexión final de núcleo elevado ( $\underline{\text { dona }}$ 'm la $\underline{\mathbf{m a}}$ )

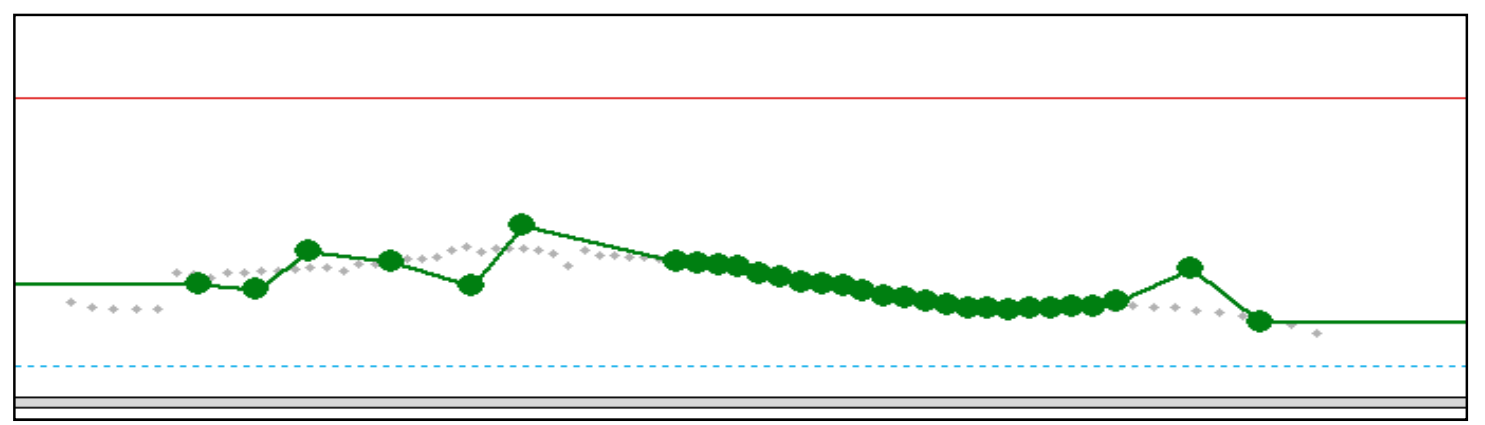

Figura 13. Manipulación del mismo enunciado con inflexiones internas y final con núcleo elevado.

\subsubsection{Resultados de la fase perceptiva}

Los 99 informantes del experimento (oyentes) determinaron los cambios de significación que aportan las modificaciones de los rasgos melódicos manipulados respondiendo a las siguientes preguntas:

\begin{tabular}{|l|l|l|}
\hline \multicolumn{1}{|c|}{ para los insultos: } & \multicolumn{1}{c|}{ para las órdenes: } & para las confrontaciones: \\
\hline $\begin{array}{l}\text { está enfadado y quiere } \\
\text { ofender }\end{array}$ & $\begin{array}{l}\text { es una orden dada con } \\
\text { autoridad }\end{array}$ & $\begin{array}{l}\text { parece que busca la } \\
\text { confrontación }\end{array}$ \\
\hline $\begin{array}{l}\text { parece que no quiere ofender } \\
\text { claramente }\end{array}$ & $\begin{array}{l}\text { más que una orden parece un } \\
\text { ruego }\end{array}$ & $\begin{array}{l}\text { parece que busca la } \\
\text { cooperación }\end{array}$ \\
\hline
\end{tabular}

En la tabla 1 se muestran los porcentajes totales de acierto respecto a la intención con la cual habían sido grabados los originales. Se esperaba que los enunciados originales fueran percibidos como descorteses y los manipulados como atenuadores. Como habíamos hipotetizado, la mayoría de los insultos, las órdenes y las confrontaciones originales (excepto tres que no superaron el 50\%) fueron percibidas como descorteses con altos porcentajes de acierto.

\begin{tabular}{|c|c|c|}
\hline CATEGORIA & ENUNCIADO & $\begin{array}{c}\text { PORCENTAJE DE } \\
\text { DESCORTESÍA }\end{array}$ \\
\hline Insulto & ets imbécil & $\mathbf{9 6 , 2}$ \\
\hline Orden & dona'm la mà & $\mathbf{7 3 , 5}$ \\
\hline Confrontación & no estic d'acord amb tu & $\mathbf{6 9 , 8}$ \\
\hline Insulto & em fas fàstic, tia & $\mathbf{9 6 , 2}$ \\
\hline Orden & tanca la porta & 45,2 \\
\hline Confrontación & no puc més, em tens farta & $\mathbf{6 7 , 9}$ \\
\hline Insulto & ves-te'n a cagar & 41,5 \\
\hline Orden & tanca la porta & $\mathbf{6 0 , 3}$ \\
\hline Confrontación & Això és mentida & $\mathbf{8 4 , 9}$ \\
\hline Insulto & ets imbécil & $\mathbf{5 6 , 6}$ \\
\hline Orden & calla ja & $\mathbf{7 5 , 4}$ \\
\hline Confrontación & no em sembla bé & 45,2 \\
\hline
\end{tabular}

Tabla 1. Porcentajes en la consideración de los enunciados originales descorteses 
En la tabla 2 observamos los porcentajes en los que el rasgo melódico manipulado ha implicado una atenuación en el enunciado. A continuación, exponemos la nomenclatura y la explicación de cada rasgo:

- IFI: corresponde a la manipulación de la inflexión final introduciendo un final interrogativo, con un porcentaje de ascenso superior al $70 \%$.

- IFD: en la manipulación se introduce un final descendente.

- IFS: en la manipulación se introduce un final suspendido, con un porcentaje de ascenso no superior al $40 \%$.

- IFNE: en la manipulación se introduce un final con núcleo elevado.

- EP: corresponde a las manipulaciones de una sola palabra enfatizándola con una inflexión ascendente en la vocal tónica.

- II: corresponde a la manipulación que introducía inflexiones en las vocales tónicas internas del enunciado dejando intacta la inflexión final.

- PA: corresponde a la manipulación que modificaba la prominencia de las vocales, en estos casos se eliminaba la prominencia de las tónicas y se introducía en las átonas.

\begin{tabular}{|c|c|}
\hline $\begin{array}{c}\text { CÓDIGOS MANIPULACIÓN } \\
\text { SENCILLA }\end{array}$ & PORCENTAJE DE ATENUACIÓN \\
\hline IFI & $\mathbf{9 6 , 2}$ \\
\hline IFD & $\mathbf{7 3 , 5}$ \\
\hline EP & $\mathbf{6 9 , 8}$ \\
\hline IFS & $\mathbf{9 6 , 2}$ \\
\hline II & 45,2 \\
\hline PA & $\mathbf{6 7 , 9}$ \\
\hline IFNE & 41,5 \\
\hline
\end{tabular}

Tabla 2. Porcentajes en los que el rasgo melódico manipulado ha implicado una atenuación en el enunciado.

Como podemos observar, los rasgos melódicos que llevan a percibir el enunciado como más atenuador con este tipo de manipulaciones son: las inflexiones finales interrogativas, las inflexiones finales suspensas, los énfasis de palabra y las prominencias en vocales átonas. Curiosamente, en nuestro corpus no había aparecido ningún enunciado cortés que empleara como rasgo atenuante la melodía interrogativa; sin embargo, los resultados de las pruebas perceptivas son muy claros siendo percibido en un $96,2 \%$ como atenuador. En cambio, el otro rasgo melódico que añadimos a nuestro experimento porque era relevante en español (inflexiones internas), en catalán no parece que aporten ese valor atenuador.

Por último, mostramos la tabla de porcentajes de los enunciados con dos tipos de manipulaciones combinadas (V. tabla 3):

- Inflexiones internas (II) más inflexiones finales con núcleo elevado (IFNE)

- Inflexiones internas (II) más inflexiones finales suspensas (IFS)

- Prominencias en átonas (PA) más inflexiones finales con núcleo elevado (IFNE)

- Prominencias en átonas (PA) más inflexiones finales suspensas (IFS)

- Prominencias en átonas (PA) más inflexiones finales descendentes (IFD) 


\begin{tabular}{|c|c|}
\hline $\begin{array}{c}\text { CÓDIGOS MANIPULACIÓN } \\
\text { COMBINADA }\end{array}$ & $\begin{array}{c}\text { PORCENTAJE DE } \\
\text { ATENUACIÓN }\end{array}$ \\
\hline II+IFNE & $\mathbf{6 7 , 9}$ \\
\hline II+IFS & $\mathbf{8 4 , 9}$ \\
\hline PA+IFNE & $\mathbf{6 2 , 2}$ \\
\hline PA+IFS & 41,5 \\
\hline PA+IFD & 49 \\
\hline
\end{tabular}

Tabla 3. Porcentajes en los que la manipulación combinada ha implicado una atenuación en el enunciado.

Como podemos observar, el rasgo de las inflexiones internas se convierte en atenuador cuando se combina con una inflexión final con núcleo elevado y cuando se combina con una inflexión final suspensa, justo como sucedía en el caso de la atenuación del español coloquial (Devís 2011: 58). Observamos que el rasgo de las inflexiones internas ha sido percibido como atenuador en un $45,2 \%$ de los casos cuando aparece solo, mientras que cuando se le añade una inflexión final con núcleo elevado aumenta al $67,9 \%$ y con una inflexión suspensa hasta un $84,9 \%$. En cambio, las prominencias en átonas es un rasgo melódico que marca atenuación sobre todo cuando aparece solo o cuando va acompañado de una inflexión final con núcleo elevado.

\subsubsection{Modelos melódicos de cortesía con efecto atenuador}

A partir de la descripción acústica del corpus y de su sucesiva validación experimental en la fase perceptiva, podemos concluir que los rasgos melódicos más rentables de la cortesía atenuadora en catalán (capaces de convertir, por ejemplo, órdenes en ruegos o confrontaciones en cooperaciones) son, por orden de eficacia:

1. Enunciados con una inflexión final interrogativa.

2. Enunciados con una inflexión final suspensa (con ascenso final entre el $15 \mathrm{y}$ el $70 \%)$.

3. La combinación de inflexiones internas más una inflexión final suspensa.

4. Enunciados con una inflexión final descendente (con descenso entre el 10 y 40\%).

5. Énfasis de palabra (foco estrecho) con inflexión final de núcleo elevado (con ascenso hasta el 45\%).

6. Enunciados con prominencias en átonas (con ascensos entre el 10 y 40\%).

7. La combinación de prominencias en átonas más una inflexión final con núcleo elevado.

Los resultados, pues, permiten determinar que en catalán disponemos de un conjunto de rasgos melódicos bien definidos para expresar cortesías atenuadoras. Dicho conjunto de rasgos constituye algo parecido a un código entonativo en el que aparecen:

- Rasgos de entonación lingüística: tonemas /+ interrogativo/, /+ suspendido/ y /Interrog. -Enf. -Susp./ con un valor pragmático de cortesía (y no de pregunta, de duda o de afirmación, por ejemplo).

- Rasgos de entonación paralingüística: en entonaciones enfáticas, tales rasgos ocupan los márgenes de dispersión del tonema /+ enfático/. 
Algunos de estos rasgos melódicos, además, podrían caracterizar el perfil melódico ${ }^{8}$ de otras variedades dialectales o de otras lenguas. En Devís et al. (2017), por ejemplo, se muestra cómo la entonación prelingüística del portugués de Brasil puede entenderse, desde el español, como una entonación de cortesía, cuando en realidad es una entonación neutra en aquel idioma: así, un brasileño hablando en español (con su acento idiomático característico) será considerado un hablante muy cortés para sus interlocutores españoles, porque los rasgos de su perfil melódico coinciden, en buena parte, con los rasgos de la cortesía en español.

Otra conclusión relevante que extraemos de nuestro estudio es que, en esencia, los códigos de la entonación de cortesía del catalán y del español peninsular están muy cercanos. Los rasgos que coinciden como más atenuadores son (V. Devís, 2011):

1. Los enunciados con prominencias en átonas.

2. La combinación de inflexiones internas más una inflexión suspensa.

3. La combinación de prominencias en átonas más una inflexión final con núcleo elevado.

Aun así, se han validado rasgos en catalán que no aparecieron en el español como por ejemplo los enunciados con final descendente y otros como las inflexiones finales interrogativas o suspensas que no dieron porcentajes de atenuación tan altos en español como en catalán. Incluso también se observa que así como para el español resulta más atenuador la combinación de más de un rasgo, para el catalán la aparición de un solo rasgo, como una inflexión final interrogativa o suspensa, es suficiente para atenuar un enunciado descortés. Esto nos lleva a pensar que no son dos códigos idiomáticos claramente diferenciados, sino algo así como un único código cultural compartido.

\section{ANÁLISIS DE LOS DATOS DE LA ENTONACIÓN DE DESCORTESÍA EN CATALÁN}

\subsection{Fase acústica}

Para la interpretación de los datos hemos tenido en cuenta el modelo de Culpeper $(1996)^{9}$ (que a su vez se basa en la Teoría de Cortesía de Brown y Levison, 1978) el cual considera la descortesía como un ataque a la imagen social de los interlocutores. En su modelo, propone las siguientes superestrategias:

- Descortesía directa: el acto amenazante se realiza de forma directa, clara, con la intención de atacar la imagen positiva del interlocutor.

- Descortesía positiva: destinada a dañar la imagen positiva del destinatario y que tiene su realización en estrategias comunicativas como ignorar, desconocer, excluir al otro.

- Descortesía negativa: que apunta a dañar la imagen negativa del destinatario.

- Sarcasmo o cortesía simulada: el acto amenazante se realiza de forma insincera o de forma indirecta, mediante una implicatura.

\footnotetext{
${ }^{8}$ El concepto de "perfil melódico" lo establecimos en un trabajo anterior (Cantero y Devís, 2011) para referirnos a los rasgos melódicos que caracterizan la entonación prelingüística de los "acentos dialectales", "idiomáticos" o "extranjeros".

${ }^{9}$ El mismo que se tuvo en cuenta para el análisis de los datos del español.
} 
- Ausencia de cortesía: sin estrategias de cortesía en situaciones donde son necesarias.

En 2005, Culpeper añade una sexta categoría para dar cuenta de la descortesía encubierta, en la cual la amenaza se produce bajo forma de implicatura.

Presentamos a continuación una serie de ejemplos donde se pueden observar los principales rasgos hipotetizados como descorteses. Los rasgos encontrados fueron sucesivamente clasificados y sirvieron para realizar las pruebas perceptivas a través de su manipulación.

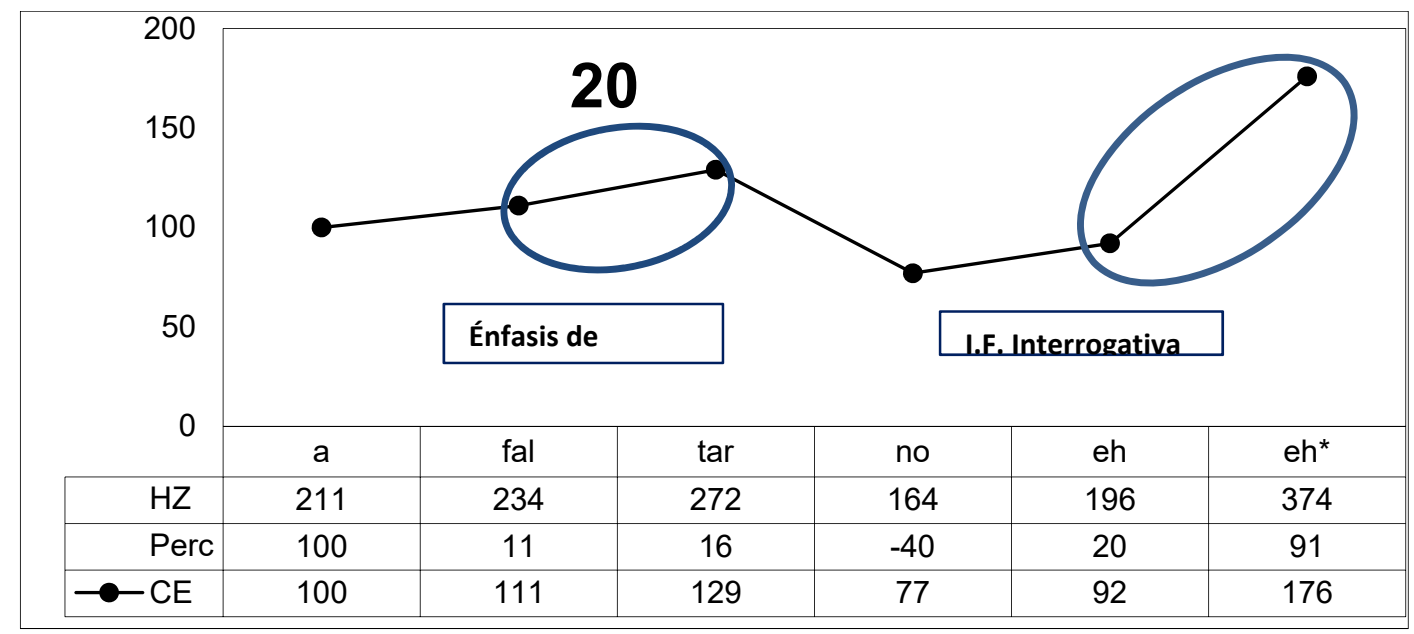

Figura 14. Melodía estandarizada del enunciado: A faltar no, eh! (Sin faltar, eh), clasificado como Descortesía directa.

La figura 14 presenta un énfasis de palabra ${ }^{10}$ que corresponde con el primer pico ${ }^{11}$ del enunciado, seguido de un descenso marcado $(-40 \%)$, lo que acentúa el énfasis de la palabra anterior, y una inflexión final ascendente $(+91 \%)$. Obtenemos así un contorno con dos ascensos marcados. En la descortesía directa los actos amenazantes que el emisor formula contra el receptor son emitidos de forma clara y evidente, o sea sin ambigüedades. En este caso el hablante le dice a su interlocutor, de manera clara y en tono ofendido, que no le falte al respeto.

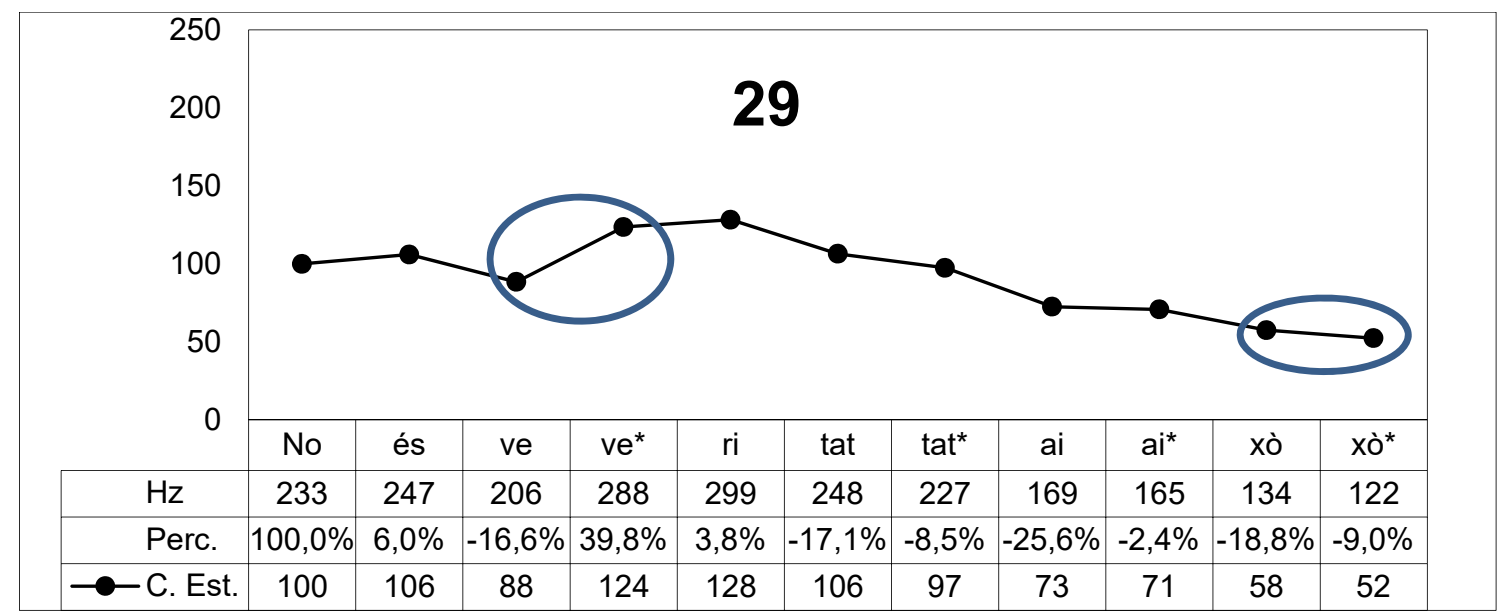

Figura 15. Melodía estandarizada del enunciado: No és veritat això (No es verdad eso).

10 Entendemos por énfasis de palabra, un foco estrecho, con una inflexión tonal ascendente en la palabra que el hablante quiere remarcar del enunciado.

${ }^{11}$ Movimiento melódico ascendente hasta la primera tónica del enunciado. 


\section{Clasificado como: descortesía directa}

La figura 15 presenta un énfasis de palabra, en este caso con un ascenso en la primera vocal átona $(39,8 \%)$ y un descenso en la tónica final $(25,6 \%)$. Le sigue una inflexión final descendente $(27,8 \%)$. Este tipo de contornos fueron validados en español como descorteses cuando la inflexión de una vocal átona superaba el 50\% de ascenso e iba seguida de un final superior al $30 \%$ de descenso. La prueba perceptiva deberá validar si estos porcentajes algo inferiores en catalán también son escuchados como descorteses. En este caso el hablante entiende que su interlocutor está diciendo mentiras y responde de manera clara ofendido.

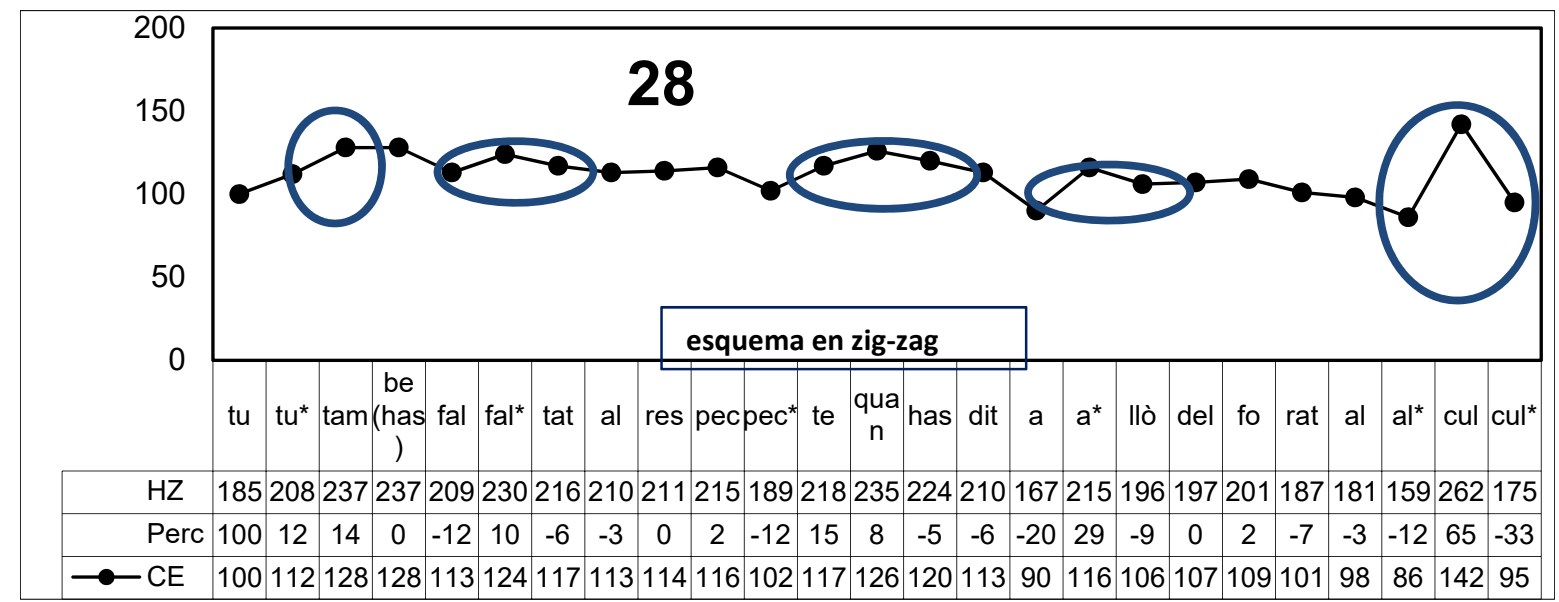

Figura 16. Melodía estandarizada del enunciado: Tu també has faltat al respecte quan has dit allò del forat al cul (Tú también has faltado al respeto cuando has dicho eso del agujero en el culo), clasificado como: descortesía negativa.

La figura 16 presenta un esquema en zigzag, con primer pico elevado y con un énfasis de palabra al final del enunciado, que marca la última tónica con una inflexión con núcleo elevado. Con esta inflexión tonal justo remarca la palabra con la que se ha sentido ofendido y que ha provocado su reacción "cul". El hablante siente que le han faltado al respeto y le dice a su interlocutor, usando un tono descortés, que él también ha faltado al respeto. La descortesía negativa trata de ofender la imagen negativa del interlocutor, en este caso resalta la imagen de irrespetuoso.

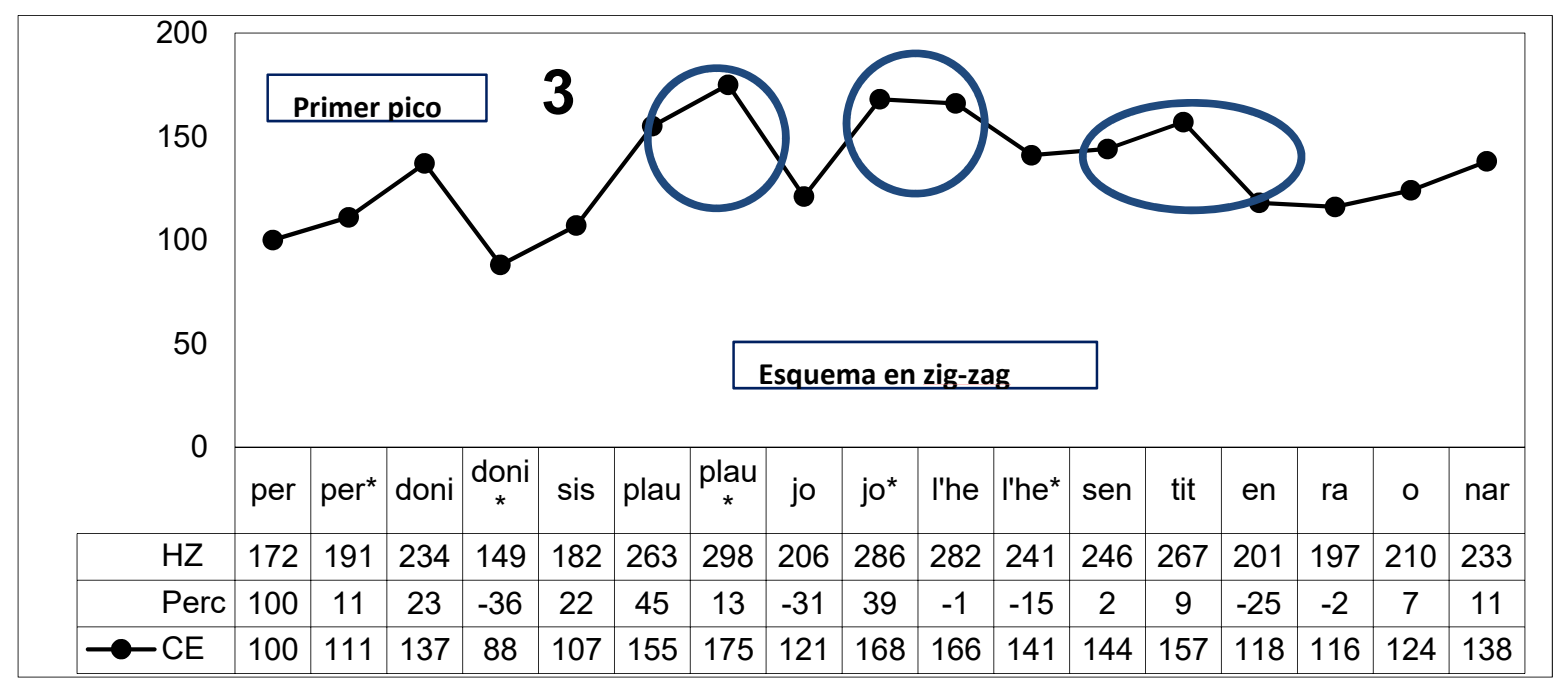

Figura 17. Melodía estandarizada del enunciado: Perdoni, si usplau, jo l'he sentit enraonar (perdone, por favor, yo le he escuchado hablar). 
En la figura 17 observamos nuevamente el contorno en zigzag con frecuentes picos ascendentes en vocales tónicas y primer pico elevado. La queja de la informante en este caso se debe a que no le dejan hablar, y resalta la imagen negativa de su interlocutor como una persona irrespetuosa. El tratamiento de usted y el énfasis en la palabra "si us plau" no debe de sorprendernos, ello ejemplifica la distancia social, y la distancia discursiva que quieren mantener. No se trata de una conversación coloquial entre amigos, el hablante se juega su imagen en público y por tanto cuida cada detalle.

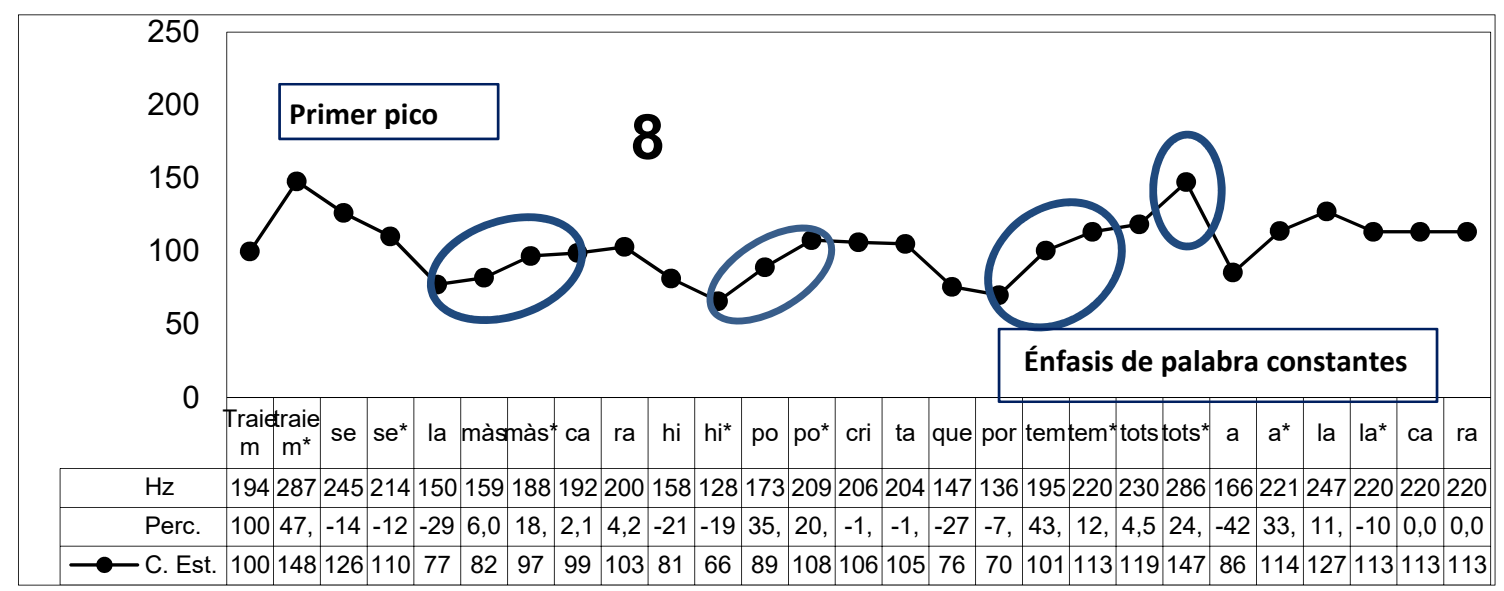

Figura 18. Melodía estandarizada del enunciado: Traiem-se la máscara hipócrita que portem tots a la cara (quitémonos la máscara hipócrita que llevamos todos en la cara), clasificado como descortesía directa.

La figura 18 presenta el mismo esquema en zigzag con énfasis de palabra constantes, primer pico elevado ( $48 \%$ de ascenso) y final descendente ( $11 \%$ de descenso). Observamos un 56\% de ascenso en la tónica de "hipócrita", un 56\% también en la tónica de "portem" y un $29 \%$ de ascenso en la tónica "tots" que inicia en la palabra anterior. Este tipo de contornos con inflexiones ascendentes en la vocales tónicas superiores al $50 \%$ fueron validados para el español como descorteses en contextos donde la imagen del hablante se viera dañada. En este caso el hablante ofendido por los comentarios de los demás interlocutores exclama, sin ambigüedades, que todos son unos hipócritas.

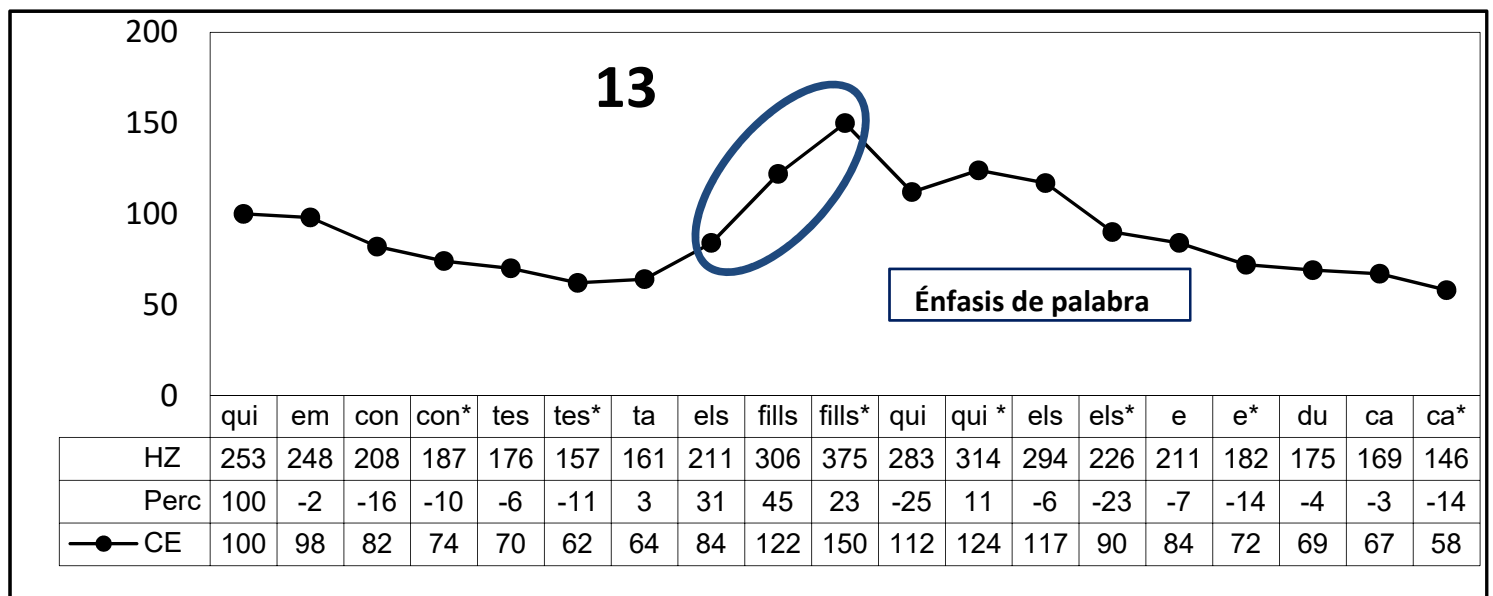

Figura 19. Melodía estandarizada del enunciado: Qui em contesta? Els fills qui els educa?

(¿Quién me contesta? ¿Los hijos quién los educa?), clasificado como: Sarcasmo o cortesía simulada. 
La figura 19 presenta dos grupos fónicos, en el primero "qui em contesta" se observa un contorno relativamente plano. El segundo, "els fills qui els educa", empieza con un énfasis de palabra, coincidiendo con el primer pico con un ascenso pronunciado (+ $68 \%$ ), seguido de una declinación descendente, creando un esquema con un solo pico. Las inflexiones ascendentes fueron validadas también como rasgos descorteses en español cuando tenían un ascenso superior al 50\%, siempre que hubiera un contexto comunicativo donde el hablante viera amenazada su imagen (Devís, 2011). En este caso el hablante se siente ofendido cuando su interlocutor le asegura estar de acuerdo con la adopción de niños por parte de parejas homosexuales. Pero el acto amenazante en este caso se realiza de forma indirecta. El hablante no se dirige al interlocutor de manera directa como en la Fig. 14, sino que lo hace lanzando una pregunta sin destinatario concreto, pero marcando con un énfasis la palabra "fills", que demuestra que el hablante no está de acuerdo con que los niños sean educados por parejas homosexuales y, de esta manera, ataca la imagen de aquellos que sí lo están sin señalarlos directamente.

Los datos analizados, pues, nos permitieron establecer una serie de rasgos melódicos en este caso para expresar la descortesía. A partir de ellos, elaboramos la siguiente hipótesis:

1) Inflexión final:

- Inflexión final neutra (con descenso no superior al 20\%)

- Inflexión final interrogativa (con ascenso por encima del 90\%)

- Inflexión final de núcleo elevado

2) Cuerpo del contorno:

- Prominencia en átonas (entre el 10 y el $40 \%$ de ascenso)

- Presencia de primeros picos

- Introducción de más de un énfasis de palabra (foco estrecho) constituyendo un contorno en zigzag (con ascensos sobre las vocales tónicas superior al 50\%)

Estos rasgos coinciden, esencialmente, con los que en investigaciones anteriores (Devís, 2011) habíamos identificado para la descortesía. Las únicas diferencias se encuentran en los casos de las inflexiones finales descendentes; en el caso del español eran descensos superiores al 30\% y en el catalán no encontramos descensos superiores al 20\%. Y en de las prominencias en átonas; donde en español superaban el $50 \%$ de ascenso y en catalán no encontramos ascensos superiores al 40\%. Nos encontramos en catalán que el mismo rasgo de las prominencias en átonas con ascensos entre el 10\% y el $40 \%$ sirve tanto para atenuar como para marcar descortesía dependiendo del contexto. Esto no ocurría en español donde este raso funcionaba entre el $10 \%$ y el $40 \%$ para la atenuación y por encima del 50\% para la descortesía. Debemos ver en las pruebas perceptivas si un porcentaje menor en estos dos rasgos también aporta un matiz de descortesía en catalán.

\subsection{Fase perceptiva}

Para poder validar los rasgos hipotetizados como descorteses se configuró de nuevo un corpus que fue creado ad hoc. En este caso los originales eran, claramente, enunciados corteses, desde el punto de vista léxico-gramatical, para asegurar que los rasgos, exclusivamente melódicos, introducidos en las manipulaciones fueran los únicos responsables de aportar un efecto descortés. Para ello se grabaron 5 halagos, 5 ruegos y 5 cooperaciones producidos por un hombre y una mujer, obteniendo un total de 30 
enunciados, los cuales fueron posteriormente manipulados con el programa de análisis acústico Praat. Los enunciados grabados fueron los siguientes:

- Halagos: Em tornes boja (me vuelves loca), Ets un home meravellós (eres un hombre maravilloso), Quines cames més maques que tens (qué piernas más bonitas tienes), Ets el noi més trempat de la festa (eres el chico más simpático de la fiesta), Els dies amb tu són increíbles (los días contigo son increíbles).

- Ruegos: Parla'm de tu (háblame de ti), M'ajudes a estendre la roba (me ayudas a tender la ropa), Seu al meu costat (siéntate a mi lado), Em deixes passar (me dejas passar), Em poses un café (me pones un café).

- Cooperaciones: em dones just el que necessito (me das justo lo que necesito), Crec que estem d'acord (creo que estamos de acuerdo), Em sembla que ho estàs fent bé (me parece que lo estás haciendo bien), Has tingut una idea brillant (has tenido una idea brillante), El que dius és veritat (lo que dices es verdad).

Cada audio sufrió 3 manipulaciones: la inflexión final descendente con descensos no superiores al $20 \%$; las prominencias en átonas con ascensos no superiores al $40 \%$, más una inflexión final descendente y el esquema en zigzag con pico elevado y ascensos en vocales tónicas hasta el $90 \%$ o superior. En total obtuvimos 90 versiones manipuladas 45 de la voz femenina y 45 de la voz masculina.

Posteriormente, elaboramos tres test perceptivos, cada uno para 33 oyentes, en total los test fueron validados por 99 oyentes hablantes nativos de catalán, todos estudiantes universitarios de la Universidad de Barcelona. En cada test ofrecimos los 12 enunciados originales y seleccionamos una versión manipulada de cada original para cada uno de los test. De este modo pudimos validar las 21 versiones originales y 45 manipuladas de las 90 disponibles.

Los objetivos fueron definir si los rasgos melódicos hipotetizados en la fase acústica podían por si solos o en interacción crear un efecto descortés en enunciados que originalmente no habían sido pronunciados con esta intención, confirmando así la existencia de un código semiestable para la expresión de la descortesía melódica también en catalán. Y también comparar los resultados con la descripción elaborada para el español coloquial (Devís, 2011), para comprobar si son códigos lingüísticos diferentes o si son compartidos no por todos los hablantes del idioma sino por una comunidad de habla determinada.

Mostramos algunos ejemplos de enunciados antes y después de su manipulación. Los gráficos muestran las curvas melódicas del enunciado original y manipulado sin estandarizar, tal y como aparecen en el programa de análisis acústico PRAAT, y después de realizar la estandarización utilizando el AMH.

En los subapartados siguientes, mostramos algunos ejemplos de enunciados analizados y su respectiva manipulación.

\subsubsection{Ruegos}

La figura 20 muestra el enunciado original pronunciado con un matiz cortés atenuador. En el mismo se puede observar la inflexión final con un descenso del $28,2 \%$, siguiendo uno de los rasgos atenuadores validados para la entonación de atenuación que hemos presentado anteriormente y que corresponde a las inflexiones finales descendentes entre 
el $20 \%$ y el $40 \%$ de descenso. La imagen también muestra una melodía plana sin primer pico típico de los contornos corteses.

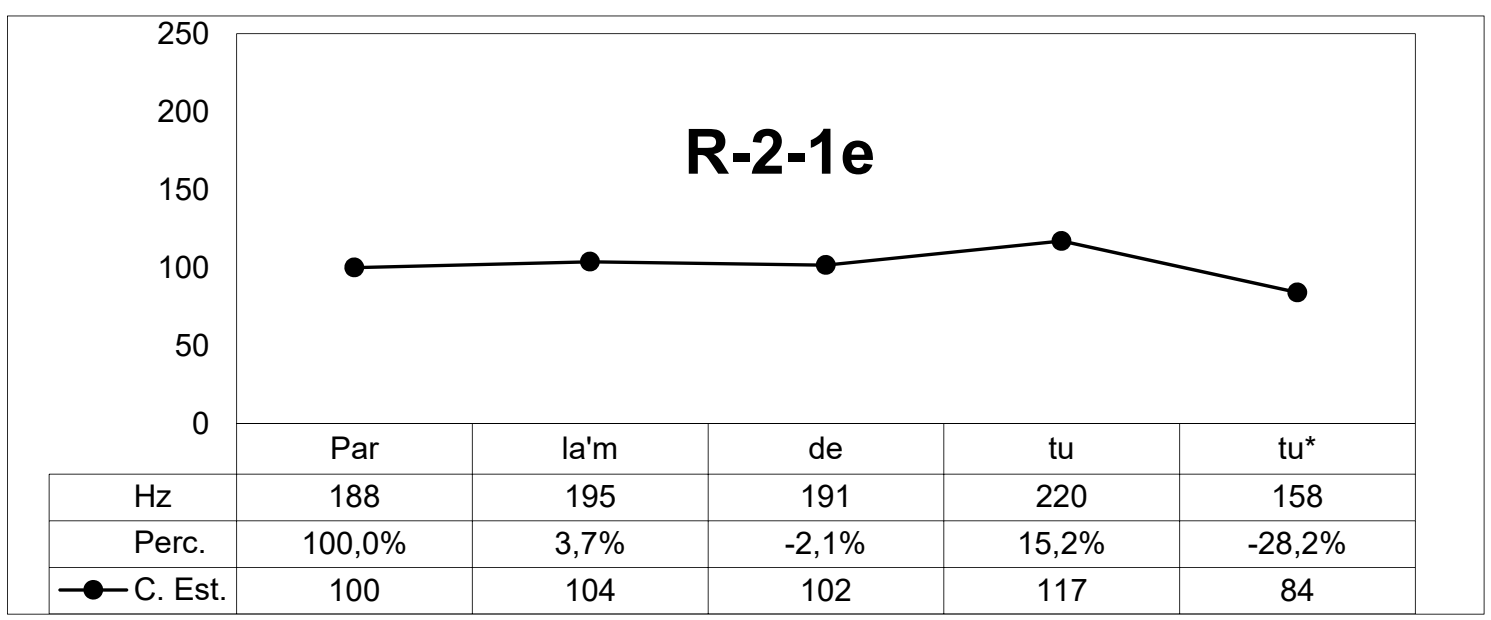

Figura 20. Melodía original del ruego: "Parla'm de tu" (Háblame de ti).

La figura 21 muestra la manipulación del anterior enunciado original. En este caso se ha aumentado la F0 del segmento tonal átono "e" $(\underline{d e})$ sin superar el 40\%.

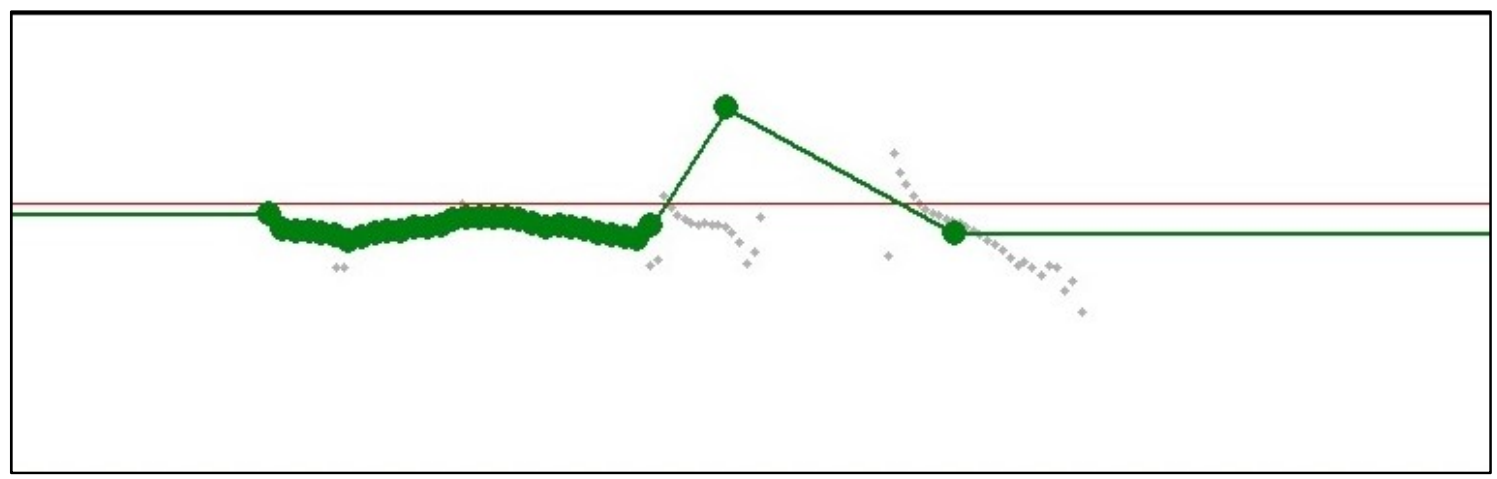

Figura 21. Melodía manipulada del ruego con prominencia en átona e inflexión final descendente

\subsubsection{Halagos}

La figura 22 muestra el enunciado original pronunciado con el mismo matiz cortés atenuador. Como se puede observar aparece una inflexión final con un descenso del $21,6 \%$, siguiendo uno de los rasgos atenuadores validados para la entonación de atenuación que hemos presentado anteriormente y que corresponde a las inflexiones finales descendentes entre el $20 \%$ y el $40 \%$ de descenso. La imagen también muestra una melodía plana típica de los contornos corteses, sin primer pico. 


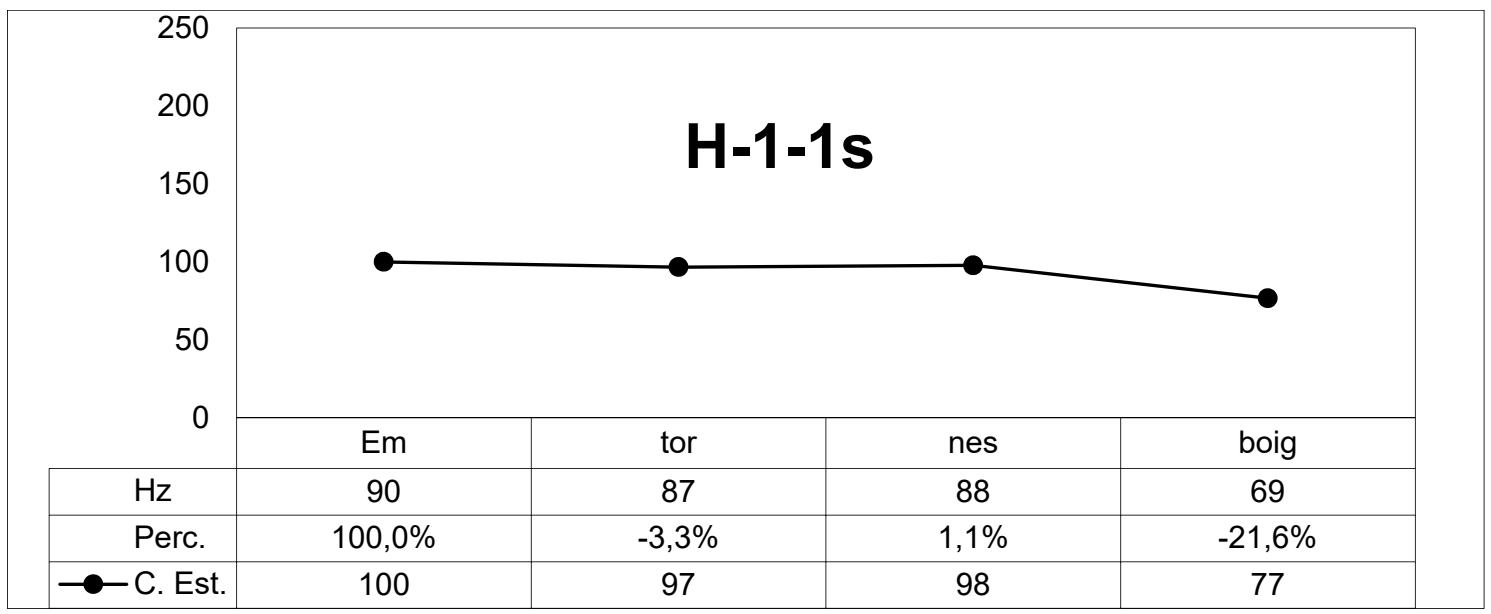

Figura 22. Melodía original del halago: "em tornes boig" (Me vuelves loco).

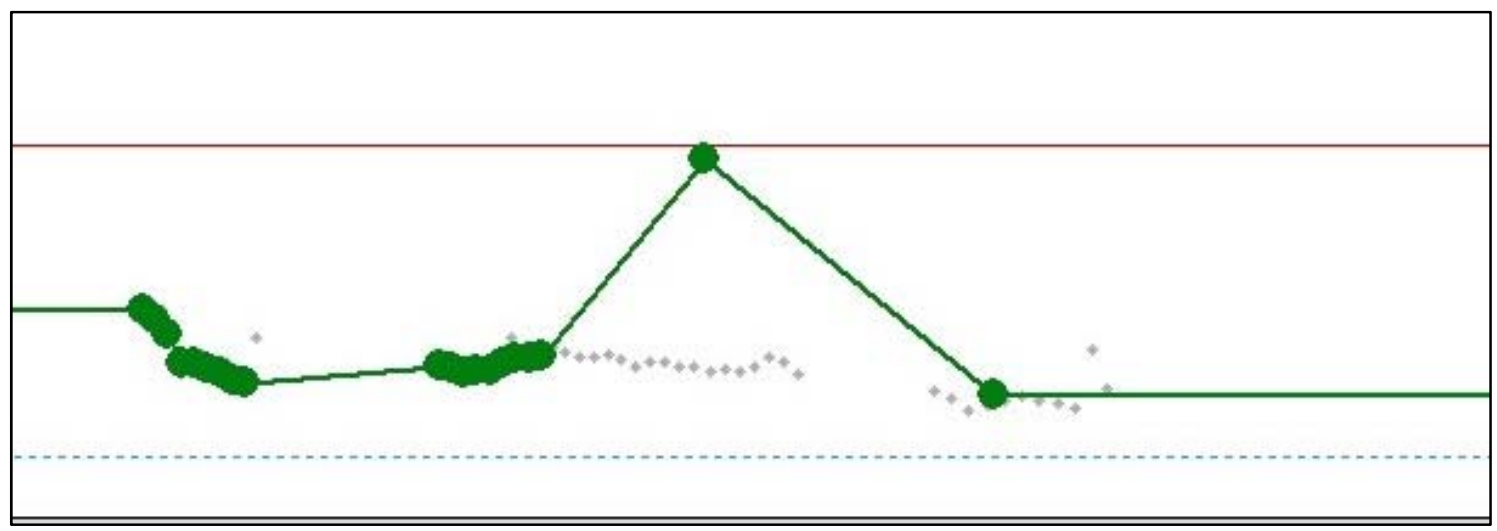

Figura 23. Melodía manipulada del halago con prominencia en átona.

La figura 23 muestra la manipulación del anterior enunciado original. En este caso se ha

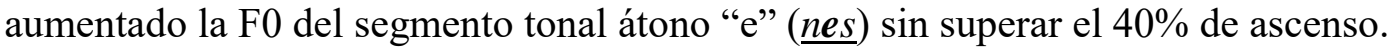

\subsubsection{Cooperaciones}

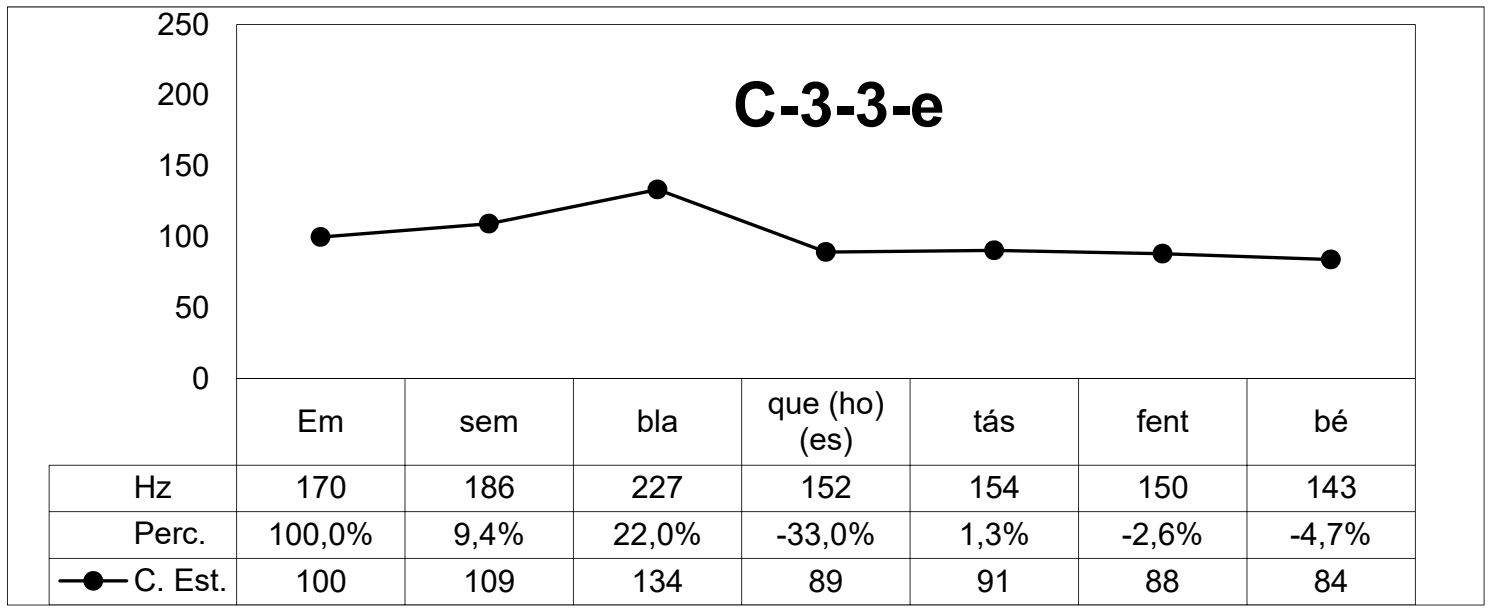

Figura 24. Melodía original de la cooperación: "em sembla que ho estàs fent bé" (Me parece que lo estás haciendo bien).

La figura 24 muestra el enunciado original pronunciado con el mismo matiz cortés atenuador. Como se puede observar aparece una prominencia del segmento tonal átono 
"a" (bla) 22\%, siguiendo uno de los rasgos atenuadores validados para la entonación de atenuación que hemos presentado anteriormente y que corresponde a las prominencias en átonas con un ascenso no superior al $40 \%$.

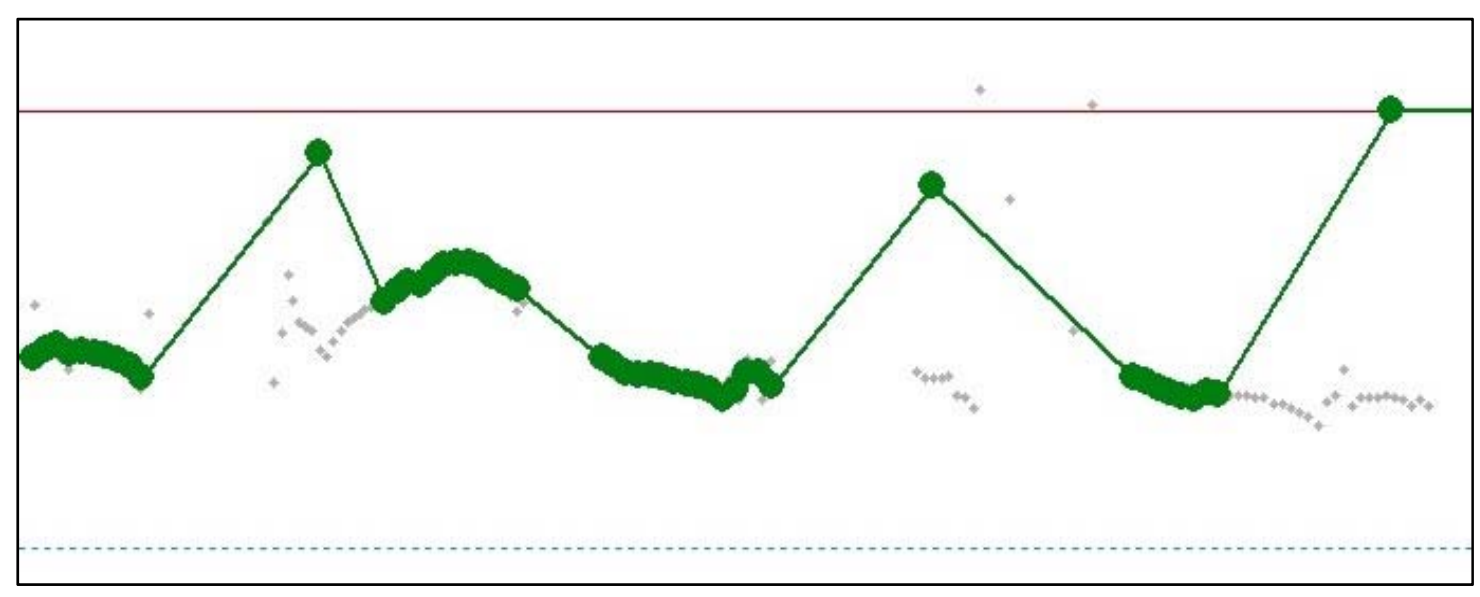

Figura 25. Melodía manipulada de la cooperación con un esquema en zigzag con ascensos sobre las vocales tónicas: compuesto por primer pico, énfasis interno de palabra y final ascendente.

La figura 25 muestra la manipulación del anterior enunciado original. En este caso se ha generado un contorno en zigzag con el aumento de la F0 de los segmentos tónicos "e" ( $\underline{\text { sem) }}$, "a" (tàs) y "e" (bé), con ascensos por encima del 50\%.

\subsubsection{Resultados de la fase perceptiva}

Los jueces del experimento (oyentes) determinaron los cambios de significación que aportan las modificaciones de los rasgos melódicos manipulados respondiendo a las siguientes preguntas:

\begin{tabular}{|l|l|l|}
\hline \multicolumn{1}{|c|}{ para los halagos: } & \multicolumn{1}{c|}{ para los ruegos: } & \multicolumn{1}{c|}{ para las confrontaciones: } \\
\hline es claramente un halago & es claramente un ruego & $\begin{array}{l}\text { busca claramente la } \\
\text { cooperación }\end{array}$ \\
\hline $\begin{array}{l}\text { más que un halago parece } \\
\text { una ofensa o una ironía }\end{array}$ & $\begin{array}{l}\text { más que un ruego parece } \\
\text { una orden o una queja }\end{array}$ & $\begin{array}{l}\text { parece que busca la } \\
\text { confrontación o la ironía }\end{array}$ \\
\hline
\end{tabular}

En la tabla 4 se muestran los porcentajes totales de acierto respecto a la intención con la cual habían sido grabados los originales. Se esperaba que los enunciados originales fueran percibidos como corteses y los manipulados como descorteses. Como habíamos hipotetizado la mayoría de los halagos, ruegos y cooperaciones originales fueron percibidas como corteses con altos porcentajes de acierto (por encima del 60\%):

\begin{tabular}{|l|c|c|}
\hline \multicolumn{1}{|c|}{ CATEGORIA } & ENUNCIADO & $\begin{array}{c}\text { PORCENTAJE DE } \\
\text { ATENUACIÓN }\end{array}$ \\
\hline Halago & Em tornes boja & 47 \\
\hline Halago & Ets un home meravellós & $\mathbf{9 4}$ \\
\hline Halago (voz femenina) & $\begin{array}{c}\text { Quines cames més maques que } \\
\text { tens }\end{array}$ & $\mathbf{6 0}$ \\
\hline Halago (voz femenina) & Ets el noi més trempat de la festa & $\mathbf{8 5}$ \\
\hline Halago (voz femenina) & Els dies amb tu són incrëbles & $\mathbf{9 1}$ \\
\hline
\end{tabular}




\begin{tabular}{|l|c|c|}
\hline Ruego (voz femenina) & no puc més, em tens farta & 90 \\
\hline Ruego (voz femenina) & Seu al meu costat & $\mathbf{8 7}$ \\
\hline Cooperación (voz femen.) & Em dones just el que necessito & 94 \\
\hline Cooperación (voz femen.) & Em sembla que ho estàs fent bé & $\mathbf{7 2}$ \\
\hline Cooperación (voz femen.) & El que dius és veritat & $\mathbf{6 8}$ \\
\hline Halago (voz masculina) & Em tornes boig & $\mathbf{8 8}$ \\
\hline Halago (voz masculina) & $\begin{array}{c}\text { Ets la dona més trempada de la } \\
\text { festa }\end{array}$ & $\mathbf{6 4}$ \\
\hline Halago (voz masculina) & $\begin{array}{c}\text { Quines cames més maques que } \\
\text { tens }\end{array}$ & $\mathbf{6 6}$ \\
\hline Halago (voz masculina) & M'ajudes a estendre la roba & $\mathbf{8 8}$ \\
\hline Halago (voz masculina) & Em deixes passar & $\mathbf{6 7}$ \\
\hline Halago (voz masculina) & Em poses un cafè & $\mathbf{9 6}$ \\
\hline Halago (voz masculina) & Em dones just el que necessito & $\mathbf{6 2}$ \\
\hline Halago (voz masculina) & Crec que estem d'acord & $\mathbf{8 3}$ \\
\hline Halago (voz masculina) & Em sembla que ho estàs fent bé & $\mathbf{6 1}$ \\
\hline Halago (voz masculina) & Has tingut una idea brillant & \\
\hline
\end{tabular}

Tabla 4. Porcentajes en la consideración de los enunciados originales corteses.

En la tabla 5 observamos los porcentajes en los que el rasgo melódico manipulado ha implicado una descortesía en el enunciado. En este caso solo se han modificado las inflexiones finales generando una inflexión final descendente no superior al $20 \%$ de descenso.

\begin{tabular}{|c|c|}
\hline $\begin{array}{c}\text { CÓDIGOS MANIPULACIÓN } \\
\text { SENCILLA }\end{array}$ & PORCENTAJE DE DESCORTESÍA \\
\hline E-1-4 IFD & $\mathbf{5 3}$ \\
\hline E-1-5 IFD & $\mathbf{7 2}$ \\
\hline E-2-1 IFD & $\mathbf{9 4}$ \\
\hline E-2-3 IFD & $\mathbf{8 4}$ \\
\hline E-3-3 IFD & 24 \\
\hline $1-1$ IFD & $\mathbf{8 0}$ \\
\hline $1-3$ IFD & $\mathbf{5 8}$ \\
\hline $2-2$ IFD & $\mathbf{9 2}$ \\
\hline $2-4$ IFD & $\mathbf{6 9}$ \\
\hline $2-5$ IFD & $\mathbf{8 8}$ \\
\hline
\end{tabular}

Tabla 5. Porcentajes en los que el rasgo melódico manipulado de la inflexión final descendente ha implicado una descortesía en el enunciado.

Como podemos observar esta simple manipulación de la inflexión final con un descenso no superior al $20 \%$ ha sido percibido en la mayoría de los casos como más descortés respecto a la versión original sin manipular.

En la tabla 6 observamos los porcentajes en los que otro rasgo melódico manipulado ha implicado una descortesía en el enunciado. En este caso solo se ha generado un contorno en zigzag aumentando la F0 de las vocales tónicas del enunciado, con ascensos por encima del $50 \%$. 


\begin{tabular}{|c|c|}
\hline $\begin{array}{c}\text { CÓDIGOS MANIPULACIÓN } \\
\text { ZIGZAG }\end{array}$ & PORCENTAJE DE DESCORTESÍA \\
\hline E-1-2 ZZ & $\mathbf{8 8 \%}$ \\
\hline E-1-3 ZZ & $48 \%$ \\
\hline E-1-4 ZZ & $\mathbf{8 0 \%}$ \\
\hline E-1-5 ZZ & $\mathbf{9 6 \%}$ \\
\hline E-2-1 ZZ & $\mathbf{8 8 \%}$ \\
\hline E-3-1 ZZ & $\mathbf{8 9 \%}$ \\
\hline E-3-2 ZZ & $\mathbf{7 6 \%}$ \\
\hline E-3-3 ZZ & $\mathbf{8 9 \%}$ \\
\hline E-3-4 ZZ & $\mathbf{6 7 \%}$ \\
\hline $2-2 \mathrm{ZZ}$ & $\mathbf{9 2 \%}$ \\
\hline $3-1 \mathrm{ZZ}$ & $\mathbf{7 6 \%}$ \\
\hline
\end{tabular}

Tabla 6. Porcentajes en los que el rasgo melódico manipulado del contorno en zigzag ha implicado una descortesía en el enunciado.

Como podemos observar esta simple manipulación del contorno en zigzag aumentando la F0 de las vocales tónicas del enunciado, con ascensos por encima del 50\%, también ha sido percibido en la mayoría de los casos como más descortés respecto a la versión original sin manipular.

Por último, mostramos la tabla de porcentajes de los enunciados con una doble manipulación:

- Prominencias en átonas (PA) más inflexiones finales descendentes (IFD)

\begin{tabular}{|c|c|}
\hline $\begin{array}{c}\text { CÓDIGOS MANIPULACIÓN } \\
\text { COMBINADA }\end{array}$ & $\begin{array}{c}\text { PORCENTAJE DE } \\
\text { DESCORTESÍA }\end{array}$ \\
\hline E-1-1 PA+ IFD & 42 \\
\hline E-1-5 PA+ IFD & $\mathbf{7 5}$ \\
\hline E-2-1 PA+ IFD & $\mathbf{8 6}$ \\
\hline E-2-3 PA+ IFD & $\mathbf{9 7}$ \\
\hline E-3-5 PA+ IFD & $\mathbf{6 4}$ \\
\hline 1-3 PA+ IFD & $\mathbf{7 6}$ \\
\hline 1-4 PA+ IFD & $\mathbf{5 6}$ \\
\hline 2-2 PA+ IFD & $\mathbf{7 6}$ \\
\hline 2-4 PA+ IFD & $\mathbf{6 7}$ \\
\hline 3-2 PA+ IFD & $\mathbf{6 0}$ \\
\hline $3-3$ PA+ IFD & $\mathbf{8 3}$ \\
\hline 3-4 PA+ IFD & 48 \\
\hline
\end{tabular}

Tabla 7. Porcentajes en los que en los que la manipulación combinada ha implicado ha implicado una descortesía en el enunciado.

Como podemos observar esta manipulación combinada de aumento de la F0 en vocales átonas, con ascensos entre el 10\% y el $40 \%$, más una inflexión final descendente, no superior al $20 \%$ de descenso, también ha sido percibido en la mayoría de los casos como más descortés respecto a la versión original sin manipular. 


\subsubsection{Modelos melódicos de descortesía}

A partir de la descripción acústica del corpus y de su sucesiva validación experimental en la fase perceptiva, podemos concluir que los rasgos melódicos más rentables de la descortesía en catalán (capaces de convertir, por ejemplo, ruegos en órdenes o cooperaciones en confrontaciones) son, por orden de eficacia:

1. La combinación de prominencias en átonas (con un ascenso entre el $10 \%$ y el $40 \%$ ) más una inflexión final descendente (no superior al 20\%).

2. La introducción de más de un énfasis de palabra constituyendo un contorno en zigzag (con pico elevado y ascensos sobre las vocales tónicas superior al 50\%).

Los resultados, pues, permiten determinar que en catalán también disponemos de un conjunto de rasgos melódicos bien definidos para expresar la descortesía. Dicho conjunto de rasgos melódicos constituye algo parecido a un código entonativo en el que aparecen:

- Rasgos de entonación lingüística: tonemas /-Interrog. -Enf. -Susp./ con un valor pragmático de descortesía (y no de afirmación, por ejemplo).

- Rasgos de entonación paralingüística: en entonaciones enfáticas, tales rasgos ocupan los márgenes de dispersión del tonema /+ enfático/.

Otra conclusión relevante que extraemos de nuestro estudio es que los códigos de la entonación de descortesía del catalán y del español peninsular son prácticamente idénticos. Solo se ha podido observar que para el catalán la inflexión final descendente con efecto descortés no supera el $20 \%$ de descenso, mientras que en español llega al $30 \%$; y que las prominencias en átonas con ascensos entre el $10 \%$ y el $40 \%$ junto a esta inflexión descendente son también consideradas como rasgo de descortesía. Estos son los rasgos que se pudieron validar para el español por orden de eficacia (V. Devís, 2011):

1. La introducción de más de un énfasis de palabra constituyendo un contorno en zigzag (con ascensos sobre las vocales tónicas superior al 50\%).

2. La combinación de prominencias en átonas (con un ascenso superior al $50 \%$ ) más una inflexión final descendente (superior al 30\%).

\section{CONCLUSIONES}

Los resultados obtenidos, validados mediante las pruebas perceptivas, confirman las hipótesis de que existe un código "semiestable" para la expresión de la (des)cortesía melódica del catalán, pero también nos confirman que este no forma parte del código lingüístico de la lengua catalana (que en la entonación serían exclusivamente los rasgos fonológicos), compartido por todos los hablantes del idioma, sino de los códigos paralingüísticos, compartidos no por todos los hablantes del idioma sino por una comunidad de habla determinada. En este sentido, el código descrito para el español coloquial peninsular que sirve para expresar una entonación (des)cortés también funcionaría en catalán, con las pequeñas diferencias encontradas, pues la comunidad de habla que lo utiliza es la misma.

Estos resultados nos llevan a pensar que seguramente existen códigos culturales "semiestables", socialmente compartidos, útiles en este caso tanto para los hablantes de catalán como para los hablantes de español, cercanos a lo que serían códigos lingüísticos al uso, pero que exceden los límites estrictamente idiomáticos. Esta sería una característica de las lenguas que se encuentran permanentemente en contacto. 
Hay que decir que la identificación de estos códigos culturales "semiestables" para la entonación de la (des)cortesía de ambas lenguas, resultará muy útil para emplearse como modelo didáctico en la enseñanza de la lengua, especialmente como lengua extranjera: en niveles iniciales, para implementar la comprensión oral también desde parámetros culturales; y en niveles avanzados, para implementar esos rasgos característicos del habla en el desarrollo de las competencias orales en producción e interacción. Para ello deberemos seguir estudiando y llenando progresivamente el vacío temático sobre las funciones pragmáticas de la entonación y, sobre todo, para llegar a un conocimiento global e integrado de la fenomenología prosódica que permita, cada vez más, la comprensión de los fenómenos que intervienen en la comunicación oral y su transposición didáctica.

\section{REFERENCIAS BIBLIOGRÁFICAS}

Albelda Marco, Marta (2005): La intensificación en el español coloquial. Servicio de Publicaciones de la Universitat de València, CD-Rom.

Albelda, Marta; Briz, Antonio; Mancero Cestero, Ana Maria; Kotwica, Dorota; Villalba Ibáñez, Cristina. (2014): "Ficha metodológica para el análisis pragmático de la atenuación en corpus discursivos del español (es.por.atenuación)". Oralia 17, $7-62$.

Álvarez, Alejandra; Blondet, Maria Alejandra (2003): “Cortesía y prosodia: un estudio de la frase cortés en el español de Mérida (Venezuela)". En Martín Butragueño, Pedro; Herrera Zendejas, Esther. (eds.), La tonía. Dimensiones fonéticas y fonológicas, México: El Colegio de México, 319-330.

Astruc, Lluïsa (2008): "Cortesia y entonacion: las interrogativas absolutas en catalán", Revista de Letras 7, 41-53.

Briz, Antonio; Hidalgo, Antonio (2008): "Marcadores discursivos y prosodia: observaciones sobre su papel modalizador atenuante". En Albelda, Marta: Briz, Antonio; Contreras, Josefa; Hernández, Nieves; Hidalgo, Antonio (eds.), Cortesía y conversación: de lo escrito a lo oral. III Coloquio Internacional del programa, 390-409. http//:www.edice.org/descargas/3coloquioEDICE.pdf, [28/11/2020]

Brown, Penelope; Stephen Levinson (1987 [1978]): Politeness. Some universals in language usage. Cambridge University Press.

Cantero Serena, Francisco José (1999): "Análisis melódico del habla: principios teóricos y procedimientos". Actas del I Congreso de Fonética Experimental, Tarragona, 127-133.

Cantero Serena, Francisco José (2002): Teoría y análisis de la entonación, Barcelona: Edicions de la Universitat de Barcelona.

Cantero Serena, Francisco José; Font-Rotchés, Dolors (2007): "Entonación del español peninsular en habla espontánea: patrones melódicos y márgenes de dispersión”, Moenia 13, 69-92.

Cantero Serena, Francisco José; Font-Rotchés, Dolors (2009). Protocolo para el análisis melódico del habla. Estudios de Fonética Experimental 18, 17-32.

Cantero Serena, Francisco José; Font-Rotchés, Dolors (2020). Melodic Analysis of Speech (MAS). Phonetics of Intonation. En: Abasolo Isasa, Juan; de Pablo Delgado, Irati; Ensunza Aldamizetxebarria, Ariane (ed.): Contributions on education. Universidad del País Vasco, 20-47.

Cantero Serena, Francisco José; Mateo, Miguel (2011): “Análisis melódico del habla: complejidad y entonación en el discurso". Oralia 14, 105-127. 
Cantero Serena, Francisco José (2019): “Análisis prosódico del habla: más allá de la melodía”. En Álvarez Silva, María Rosa; Muñoz Alvarado, Alex; Ruiz Miyares, Leonel (eds.), Comunicación Social: Lingüística, Medios Masivos, Arte, Etnología, Folclor y otras ciencias afines. Volumen II. Santiago de Cuba: Ediciones Centro de Lingüística Aplicada, 485-498.

Culpeper, Jonathan (1996): "Towards an anatomy of impoliteness". Journal of Pragmatics 25, 349- 367.

Devís Herraiz, Empar (2011): "Rasgos melódicos de la cortesía atenuadora en el español coloquial". Moenia 17, 475-490.

Devís Herraiz, Empar; Cantero Serena, Francisco José (2014): "The intonation of mitigating politeness in catalan", Journal of Politeness Research 10 (1), 127-149.

Devís Herraiz, Empar; Cantero Serena, Francisco José; Fonseca de Oliveira, Aline (2017): "La competencia estratégica y cultural en el aprendizaje de la entonación de (des)cortesía del español por parte de brasileños", Delta Vol. 33, No 4, 10391058 .

Font-Rotchés, Dolors (2006): Corpus oral de parla espontània. Gràfics i arxius de veu. Biblioteca Phonica 4. http://www.ub.es/lfa [28/11/2020]

Font-Rotchés, Dolors (2007): L'entonació del català, Barcelona, Publicacions de l'Abadia de Montserrat.

Font-Rotchés, Dolors (2011): "Èmfasis bàsics de l'entonació en els contorns del català central". En: Lloret, Maria Rosa; Pons, Claudia (eds.), Noves aproximación a la fonologia i la morfología del català. Alacant: Institut interuniversitari de Filologia Valenciana, 193-216.

Haverkate, Henk (1994): La cortesía verbal. Madrid, Gredos.

Herrero Fernández, Cristina; Devís Herraiz, Empar (2020): “Unintentional impolite intonation in L2 Spanish requests produced by Chinese workers living in Madrid", Proc. 10th International Conference on Speech Prosody 2020, 848-852. DOI: 10.21437/SpeechProsody.2020-173 [28/11/2020]

Hernández Flores, Nieves (2002): "Cortesía y contextos socioculturales en la conversación de familiares y amigos". Actas del Primer Coloquio del Programa EDICE. Estocolmo: Programa EDICE, 121-127.

Hidalgo, Antonio (2001): "Modalidad oracional y entonación. Notas sobre el funcionamiento pragmático de los rasgos suprasegmentales en la conversación". Moenia 7, 271-292.

Hidalgo, Antonio (2006): "La expresión de cortesía (atenuación) en español hablado: marcas y recursos prosódicos para su reconocimiento en la conversación coloquial". En Milka Villayandre (ed.), Actas del XXXV Simposio Internacional de la SEL. León: Universidad de León, 958-979.

Hidalgo, Antonio (2007): "Sobre algunos recursos fónicos del español y su proyección sociopragmática: atenuación y cortesía en la conversación coloquial". Quaderns de Filologia, Estudis Lingüístics 12, 129-142.

Hidalgo, Antonio (2009): "Modalización (des)cortés y prosodia: estado de la cuestión en el ámbito hispánico". Boletín de Filología de la Universidad de Chile XLIV/1, 161-195.

Lakoff, Robin Tolmach (1973): "The logic of politeness; or minding your p's and q's". Papers from the seventh regional meeting of the Chicago Linguistic Society 9, 292-305.

Leech, Neil Geoffrey (1983): Principles of Pragmatics. Londres: Longman.

Magraner Mifsud, Àngela (2018): “Estudi comparatiu de l'atenuació pragmàtica en la llengua catalana”. Textos en Proceso 3(2), 166-197. 
Nadeu, Marianna (2008): "The contribution of tonal scaling to the perception of politeness in Catalan". Barcelona: Universitat Pompeu Fabra. http://prosodia.upf.edu/home/arxiu/tesis/master/tesina nadeu.pdf [06/11/2020].

Nadeu, Marianna; Prieto, Pilar (2011): "Pitch range, gestural information, and perceived politeness in Catalan", Journal of Pragmatics 43(3), 841-854.

Orozco, Leonor (2008): "Peticiones corteses y factores prosódicos". En Herrera, Zendejas, Esther; Martín Butragueño, Pedro (eds.), Fonología Instrumental. Patrones fónicos y variación. México: El colegio de México, 335-355.

Payrató, Lluís (1988): Català col.loquial. Valencia: Universitat de València.

Payà, Marta (2003): "Politeness strategies in spoken Catalan: When prosodic and non prosodic elements don't match", 6th NWCL International Conference: Prosody and Pragmatics, Preston (United Kingdom).

Quilis, Antonio (1988): Fonética Acústica de la lengua espanyola. Madrid, Gredos.

Quilis, Antonio (1993): Tratado de fonética y fonología espanyola., Madrid, Gredos.

Roldán, Yasna (2000): "Correlatos acústicos de actos de habla atenuados del español de Chile". Onomazein 5, 107-118.

Roseano, Paolo; Fernández Planas, Ana María; Elvira-García, Wendy; Martínez Celdrán, Eugenio (2015): "La entonación de las preguntas parciales en catalán". Revista Española de Lingüística Aplicada 28:2, 511-554.

Waltereit, Richard (2005): "La polifonía prosódica: Copiar un patrón entonativo". Revista Internacional de Lingüística Iberoamericana III-2, 137-150. 